\title{
Review Article \\ Effect of Nanoadditives on Bitumen Aging Resistance: A Critical Review
}

\author{
Sara Filippi $\mathbb{D}^{1}{ }^{1}$ Miriam Cappello $\mathbb{D}^{1},{ }^{1}$ Manuel Merce, ${ }^{2}$ and Giovanni Polacco ${ }^{1}{ }^{1}$ \\ ${ }^{1}$ Department of Civil and Industrial Engineering, University of Pisa, Largo Lucio Lazzarino, 56122 Pisa, Italy \\ ${ }^{2}$ Centre de Recherche de Solaize, Total Marketing \& Services, Chemin du canal, 69360 Solaize, France \\ Correspondence should be addressed to Sara Filippi; sara.filippi@unipi.it
}

Received 15 June 2018; Revised 10 September 2018; Accepted 27 September 2018; Published 27 November 2018

Academic Editor: Jianbo Yin

Copyright (C) 2018 Sara Filippi et al. This is an open access article distributed under the Creative Commons Attribution License, which permits unrestricted use, distribution, and reproduction in any medium, provided the original work is properly cited.

\begin{abstract}
Starting from the eighties, the use of nanoadditives registered an increasing attention in the scientific and patent literature, especially for the case of polymeric nanocomposites. In the last decade, this involved bituminous materials, modified either with nanosized fillers or with polymeric nanocomposites. One of the expected benefits is an increased resistance of the binder to aging. After a short introduction underlining the uncertainties and risks of artefacts in aging tests, a review is given, focusing on the antiaging properties of layered silicates, which are by far the most important nanoadditives for bitumens. Together with layered silicates, other materials such as nanohydrated lime, nanosilica, and layered double hydroxides are mentioned. Preparation and characterization of the binary bitumen/layered silicate and ternary bitumen/layered silicate/polymer systems are described in order to individuate the aspects that influence the antiaging effect. Even if the available literature is quite abundant and unanimously confirms that nanoadditives may improve bitumen durability, there is a lack of studies clarifying the involved mechanisms. As it is for conventional fillers, it seems to be a combination of physical and chemical interactions. Nanoadditives with different chemistries, porosities, and interlayer spacings differently absorb the polar components from the bitumen, thus affecting their predisposition to oxidative aging.
\end{abstract}

\section{Introduction}

1.1. Aging and Aging Tests in the Presence of Mineral Fillers. Bitumen and asphalt mixtures are subjected to chemical aging that increases their oxidation degree and asphaltene content. This leads to a higher stiffness and strongly affects the performance of the pavement. Short-term aging is mainly due to volatilization of the lighter components during mixing and production, while long-term aging is due to oxidation during the in-service life. These phenomena are well known and have been deeply analysed over the last decades. Their description is not included here, since an abundant literature is already available. As an example, the interested reader is referred to the reviews by Petersen [1] and Airey [2]. The first one focuses on the aging mechanism, while the latter describes the available artificial aging procedures for bituminous binders and mixtures. From this point of view, it is important to underline the lack of normative specifically designed for modified binders, like for example mastics or polymer-modified bitumens (PMB). This is very important because the high viscosity of such binders impedes a reliable use of canonical dynamic procedures like the rolling thin film oven test (RTFOT) since the binder does not properly roll or may roll out of the bottles. To overcome these problems, alternative procedures have been proposed, such as the modified rolling thin film oven test or the rapid recovery test [2]. Lesueur et al. [3] proposed the use of a pressure aging vessel (PAV) test prolonged to $25 \mathrm{~h}$, as previously suggested by Migliori and Corté [4]. This procedure is static and the absence of the rotating phase avoid artefacts related to the high viscosity of the binder. However, when approaching the PAV test in the presence of mineral fillers, many other aspects must be taken into account like the influence of the filler on the binder density [5-7] or its tendency to sedimentation during the PAV [8]. The latter will compromise the uniformity of the sample, thus changing its permeability to oxygen molecules and affecting the whole aging process. Therefore, while testing binders modified with mineral fillers, 
there are risks of artefacts or misinterpretation of the results. It is difficult to compare different fillers, since their different behaviour may depend on intrinsic antiaging properties and/or on other properties like density, particle size distribution, porosity, specific surface area, roughness, and so on. Differences in the chosen procedure and/or filler loading are reasons why even for well-known fillers, like limestone, there are contradictory conclusions from different research groups [3]. Luckily, in the case of nanosized fillers, the abovementioned difficulties are of reduced entity for two reasons:

(1) the lower loadings (usually below $5-6 \%$ by weight) and

(2) the reduced tendency to sedimentation, due to the small dimensions of the particles.

Another critical aspect is the choice of an "aging parameter." Since oxidation alters the bitumen composition, aging evaluation may be approached starting from the wellknown fractionation proposed by Corbett [9] in saturates, naphthene aromatics, polar aromatics, and asphaltenes, in the order of their increasing molecular polarity. The changes in bitumen chemical composition can be monitored through elemental and fractional analyses, or analytical techniques, such as infrared spectroscopy $([1,10]$ and references therein, [11-25]). As an example of aging index from FTIR, Cong et al. [26] and Zhao et al. [20] define a carbonyl index as

$$
I_{C=O}=\frac{A_{C=O}}{\sum A}
$$

where $A_{C=O}$ is the area of the carbonyl band centred on $1699 \mathrm{~cm}^{-1}$ and $\sum A$ represents the total peak area between 2800 and $3000 \mathrm{~cm}^{-1}$ (necessary to normalize data obtained from films of different thicknesses).

However, the uncertainties and difficulties related to quantitative analysis from infrared spectra are very high [27] and FTIR, if used, should be coupled with other techniques to validate and confirm the results. Such techniques may follow the same philosophy of FTIR, thus comparing the composition and structures of pristine and aged bitumens. Examples could be X-ray diffraction (XRD) [28], GPC, and NMR [29]. Unfortunately, given the extremely complex chemical and structural composition of bitumen [30], these methods are always tedious and quantitatively uncertain. This is the reason why the most popular approach is a comparison of the performances before and after aging, thus defining aging indexes (AI) like

$$
\begin{aligned}
& \mathrm{AI}_{1}=P_{\mathrm{ag}}-P_{\text {or }}, \\
& \mathrm{AI}_{2}=\frac{P_{\mathrm{ag}}}{P_{\mathrm{or}}} \\
& \mathrm{AI}_{3}=\frac{\left(P_{\mathrm{ag}}-P_{\text {or }}\right)}{P_{\text {or }}},
\end{aligned}
$$

were the subscripts "ag" and "or" indicate aged and original, respectively, while $P$ is a generic property, such as penetration, viscosity, softening point, ductility, and complex modulus. This approach is simpler and quantitatively reliable, but has the disadvantage of not considering the real effects on the binder structure and chemistry. The consequence can be an incorrect or incomplete interpretation of the results. A classic example are binders modified with styrenebutadiene-styrene block copolymer (SBS), whose molecules are subjected to scission. Therefore, during aging there are two counteracting effects: (1) the loss of volatiles and increase of asphaltenes in bitumen that leads to higher stiffness and (2) degradation of SBS macromolecules that has the opposite effect (e.g., see [31] and may misleading suggest good aging resistance or even a sort of rejuvenating effect).

\section{Nanohydrated Lime}

Mineral fillers may influence the aging resistance of the binders in several ways, including chemical interactions and physical absorption of the reactive functional groups of bitumen, as well as through catalytic properties [1]. Whatever is the predominant mechanism, its amplitude strictly relates with the interfacial interactions between filler and bitumen. Since nanomaterials have a very high specific surface, they guarantee better performances than conventional micronsized mineral fillers. Alternatively, comparable antiaging effects can be obtained with lower content of nanofillers (either if used alone or in combination with conventional fillers). This is well known and the first idea that comes in mind is starting from fillers with already recognized antiaging properties, such as hydrated lime (HL). It is well known and documented that HL has a positive effect on aging and moisture damage of bituminous binders. In a dedicated review, Lesueur et al. [32], deeply analysed the antiaging mechanism, which is summarized as a combination of physical and chemical mechanisms operating on both the aggregate and bitumen. However, in contrast to the huge literature available for HL, there is still scarce literature about its nanocounterpart ( $\mathrm{nHL}$ ), probably because $\mathrm{nHL}$ is not easily accessible as a commercial product. This is why nHL is usually prepared and tested at lab scale, i.e., by mechanical milling, starting from conventional HL. The use of a Los Angeles abrasion machine leads to a "superfine HL" with $660 \mathrm{~nm}$ average size (approximately half of the parent HL) $[33,34]$. Smaller particles were obtained by using a planetary ball mill and isopropanol as the control process agent [35, 36]. Alternative to milling/abrasion is the "chemical way," followed by milling. As an example, nHL was prepared by adding $\mathrm{NaOH}$ to $\mathrm{CaCl}_{2} \cdot 2 \mathrm{H}_{2} \mathrm{O}$ under vigorous stirring, washing with water, drying, and then grounding in a mortar machine [37].

Regardless to the preparation technique, the few available papers, mainly focalize on the moisture susceptibility of nHL-modified bituminous mixtures and on the effect that aging has on the moisture damage $[38,39]$. The results indicate that both dry and wet cohesive bonds of the modified binders increase while decreasing the filler particle size.

\section{Layered Silicates (LS)}

Before considering the literature specifically dedicated to LS, it is worth remembering the meaning of the word "nano." In the case of nHL and other mineral fillers, nano is referred to 
the average diameter of the particles and the filler is mixed with bitumen while already having such dimensions. This is not true in the case of LS, which gained their "nano" prefix with the introduction of polymer nanocomposites or polymer layered silicates (PLS) in 1985 at Toyota Central R\&D Labs Inc., when Nylon-6 was mixed with montmorillonite (MMT). Since then, PLS generated great interest in the academic and industrial communities, leading to the production of a huge scientific and patent literature. It is well known that the commonly used layered phyllosilicates have a layer thickness around $1 \mathrm{~nm}$ and lateral dimensions varying from $30 \mathrm{~nm}$ to several microns. The surface charge is known as the cation-exchange capacity (CEC), generally expressed as meq/100 g [40]. This brief description explains the two main characteristics determining the use of LS as fillers for nanocomposites. The first one is their layered structure that may lead to dispersion into individual layers, thus generating particles with nanothickness. This is the abovementioned difference with respect to other nanofillers. In the case of silicates, the starting filler is in the form of a micron-sized powder that may or not shift to nano depending on its ability to separate layers one from each other. This depends on the interactions and thus on the chemical affinity with the polymer (and/or bitumen in our case). In other words, the physical mixture of a polymer and LS not necessarily generates a nanocomposite. The simple mixing of a polymer (usually hydrophobic) and native hydrophilic-LS usually leads to biphasic microcomposites with hardly improved mechanical and thermal properties. In immiscible systems, the poor physical interaction between the organic and the inorganic components leads to a classical micron-sized filler dispersion. In contrast, strong interactions between the polymer and the LS may induce dispersion of the inorganic phases at the nanometer level and thus formation of a PLS. This observation directly introduces the second characteristic, which is the possibility to change the surface chemistry through ion-exchange reactions with organic and inorganic cations. The pristine LS are only miscible with hydrophilic polymers, and to promote the interactions with hydrophobic polymers the silicate surface can be converted from hydrophilic to organophilic. This is achieved through ion-exchange reactions with organic cationic surfactants. The products are the so-called organomodified layered silicates (OLS).

Depending on the obtained dispersion, two main types of PLS nanocomposites are identified: (i) intercalated, in which the layered silicate structure still occurs in a crystallographically regular fashion, and (ii) exfoliated, in which the individual clay layers are dispersed in a continuous polymer matrix. Of course, intermediate structures, where dispersed/intercalated or intercalated/exfoliated stacks coexist, are possible and probably even more realistic. It is worth underlining that whether the dispersion at the nanometer level is obtained depends both on the chemical properties of the components and on the mixing procedure.

3.1. Bitumen/Layered Silicate Binary Systems (BLS). It is worth starting this section mentioning a couple of reviews describing the use of nanoclay-modified bitumen in asphalt mixtures $[41,42]$, where the interested reader can find an up-to-date description of the recent literature, focused on the final properties and performances. In what follows, we will specifically focus on aging and try to understand how the silicate works.

Paralleling the case of polymers, LS may be simply dispersed or intercalated/exfoliated when mixed with bitumen. In the first case, the result is a classical mastic; in the second one, it is a bitumen nanocomposite. Compared to polymers, the interactions of bitumens with LS are favoured by (1) the presence of polar functional groups in asphaltenes (like hydroxyl, carbonyl, and amine groups) and (2) the lower molecular weight, which favours insertion between the LS platelets. Nevertheless, this is not sufficient to counteract the overall hydrophobic nature of bitumen and the use of OLS helps the intercalation-exfoliation process. This is confirmed by several studies where the same LS was added to bitumen both in the modified and unmodified form [4347]. Only in a few cases was it reported that native (unmodified) LS may interact enough to form intercalated structures in the bituminous matrix $[48,49]$. As a rule, OLS will always work better than the corresponding LS since the organic modifier favours the bitumen/filler interactions. These interactions are of paramount importance to understand how the clays may act as an antiaging additive for bitumen binders.

It can be helpful to parallel this effect with the flame retardancy often observed in polymeric nanocomposites, since there are many similarities. Short-term aging is due to diffusion and evaporation of the lighter binder components, while long-term aging is due to diffusion and subsequent reaction of oxygen inside the binder. Analogously, burning needs oxygen diffusion, reaction, and then counterdiffusion of the combustion products. The presence of well-dispersed clay platelets is supposed to create a physical barrier that slows down the diffusion of small molecules through the binder. Among other possible and concomitant mechanisms, this "labyrinth effect" is deeply discussed in the literature of polymer nanocomposites and many reviews are available for the interested reader (see [50-55]). Due to the similarity with PLS, it is reasonable to suppose that the same mechanism should also work with bitumens. Thus, an antiaging effect is due to a reduction of both oxygen diffusion and evaporation of lighter components. This is a "physical" barrier. At the same time, the functional groups of the clay may chemically interact with the environment where they are dispersed, thus altering its reactivity. This adds a "chemical" factor to the antiaging mechanism. Bitumen is a mix of several constituents, with differences in polarity and functional groups. This means that the clay will selectively interact only with the most polar bitumen molecules, which are probably the more prone to aging. This selectivity may significantly accentuate the chemical contribution to the antiaging mechanism. In other words, the clay may interact exactly with the right molecules and with almost all of them. While dealing with polymers this chemical interaction is also present, but there is a fundamental difference: all polymer molecules have the same chemical composition. Therefore, the clay may not hide all polymeric functional groups. Indubitably, in the flame retardancy of polymeric nanocomposites, the physical component prevails, while both physical and chemical factors can be 


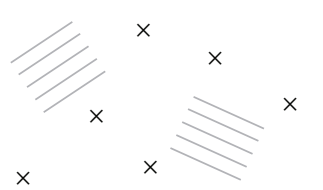

(a)

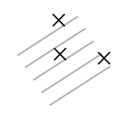

(c)

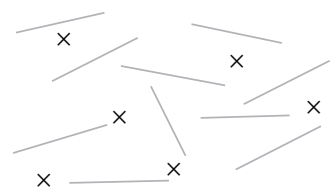

(b)

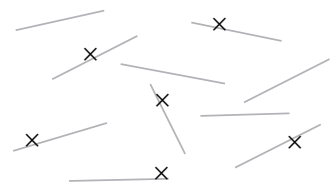

(d)
FIGURE 1: Schematic representation of the chemical/physical effect in exfoliated/intercalated nanocomposites.

important for bitumen nanocomposites. The latter point is coherent with an unexpected finding regarding bitumen nanocomposites, where the addition of clay may result in an increased flammability [56]. This may be due to the absence of interactions between clay and the nonpolar saturates, which are the lighter molecules of bitumen and thus directly involved in the ignition process. The interactions of aromatics and resins with the clay result in a lower bonding with saturates, which can be easily released, thus increasing the flammability. This is an example where the chemical component plays a fundamental role in determining the behaviour of the bitumen nanocomposites.

An interesting consequence is that exfoliation may not be indispensable in binder modification. Exfoliation is mandatory for a labyrinth effect, while for chemical interactions intercalation can be enough. This is exemplified in Figure 1, where the functional groups indicated with an " $\mathrm{X}$ " are those supposed to react with the oxygen molecules able to diffuse inside the binder. Without exfoliation and chemical interactions, the oxygen molecules and $\mathrm{X}$ functionality can easily meet and react (Figure 1(a)). The presence of an exfoliated structure lengthens the path for the oxygen molecules to reach the X-group, thus slowing down the reaction kinetic (Figure 1(b)). Analogously, interactions with the clay and intercalation into the clay galleries may engage or sterically hide the X-groups (Figure 1(c)). Obviously, both effects may be present at the same time (Figure 1(d)).

Unfortunately, due to the complexity of the nanostructures, there are no experimental procedures available to separate or directly evaluate the contribution of the chemical and physical effects during aging. At the same time, nobody did specific studies aimed at quantifying the physical barrier and the path for the oxygen molecules to reach the $\mathrm{X}$-group in the case of bituminous binders. A possible way to evaluate the physical barrier could be to study the permeation of gaseous molecules through a membrane of a binder. Comparing the permeability without nanoadditives or with nanoadditives and different loadings or degrees of intercalation/exfoliation could be helpful in this sense. This would require a dedicated study and may furnish a direct experimental evidence not available now. This is why the importance of chemical interactions was indirectly underlined by comparing the properties of BLS obtained with the same

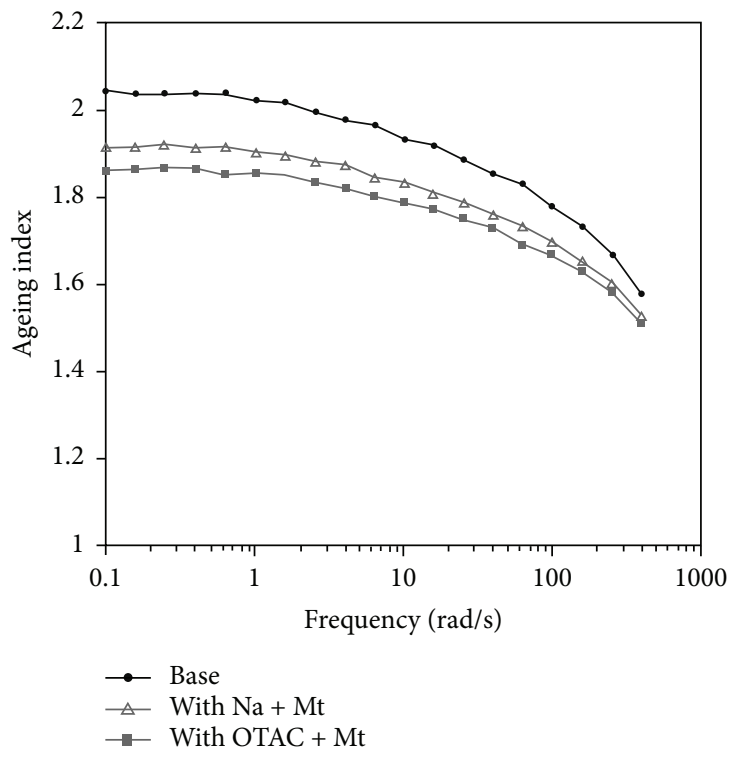

Figure 2: Aging indexes as a function of frequency at fixed temperature. In the figure legend "Base" is the unmodified bitumen, $\mathrm{Na}+\mathrm{Mt}$ is MMT, and OTAC + Mt is OMMT (Figure 9 of [44]).

materials, but with different blending conditions. Longer blending times and/or higher shearing speeds resulted in increased dispersion and exfoliation, but this was not reflected in different rheological properties of the final material [57]. This means that the effect of intercalationexfoliation on the binder properties can be helpful to discriminate the relative weight of the physical and chemical contributions. This aspect will be further discussed.

Several authors studied the aging properties of binary BLS systems. Liu et al. [44] modified a bitumen with a sodium montmorillonite both in its native form (MMT) and after organomodification with octadecyl trimethylammonium chloride (from now on, an organomodified MMT will be indicated as OMMT irrespective of the nature of the organic modifier). The XRD patterns showed that, after mixing with bitumen, the basal $d_{001}$ spacing of MMT changes from $1.3 \mathrm{~nm}$ to $1.5 \mathrm{~nm}$ thus indicating a modest intercalation of the bitumen molecules. In contrast, for OMMT the basal spacing doubles and from $2.1 \mathrm{~nm}$ to become $4.2 \mathrm{~nm}$. The higher basal spacing of OMMT with respect to MMT is due to the presence of the organomodifier, which is located between the layers. The doubling of its value after mixing with bitumen indicates strong interactions and intercalations of bitumen molecules in the interlayer space. Even though complete exfoliation was not obtained (in a previous paper the authors hypothesize exfoliation for the same OMMT [43]), it is obvious that the organomodification improves the interactions between bitumen and silicate. This is due to both the lower hydrophilicity and the higher basal spacing of OLS that facilitates the diffusion into the interlayer spacing. Short-term aging was evaluated, and the aging index was defined as in (3), with $P$ being the complex modulus before and after RTFOT. Since the rheological properties were evaluated in a frequency sweep test performed at $60^{\circ} \mathrm{C}$, $\mathrm{AI}$ is reported as a function of frequency (Figure 2) and both 


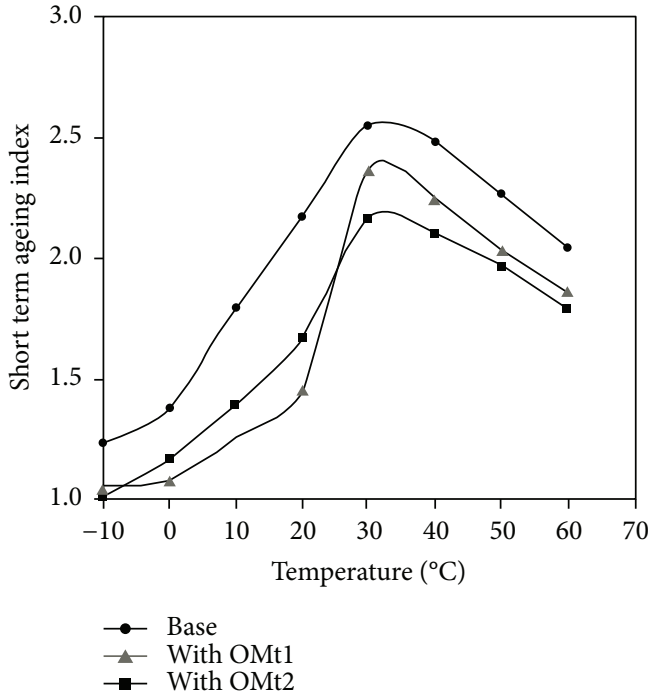

(a)

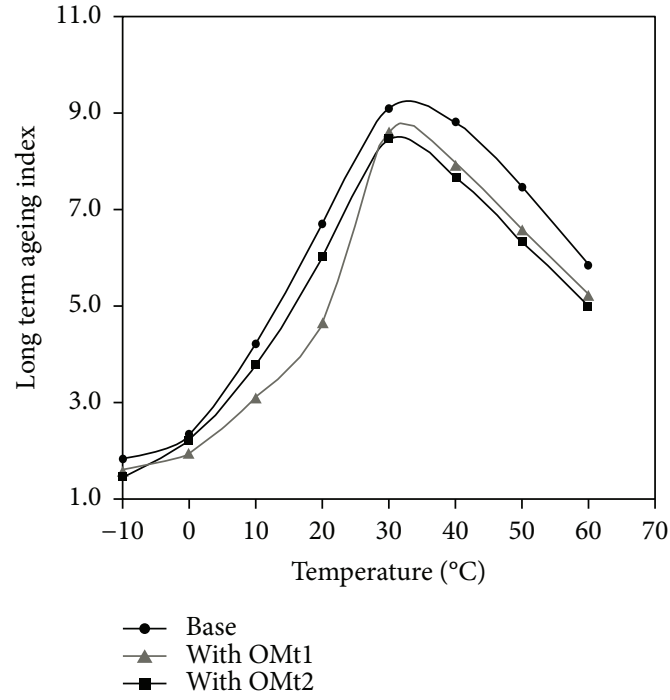

(b)

FIgURE 3: Short- (a) and long- (b) term aging indexes as a function of temperature. (Figures 9 and 10 of [58]).

silicates seem to positively affect the aging resistance, with the OMMT being slightly better than MMT.

In a subsequent paper, the same $\mathrm{AI}$ was calculated after both short- and long-term aging while using two different OMMTs, indicated as OMt1 and OMt2 [58]. In this case, AI is reported as a function of the test temperature (Figure 3) and the curves give a few interesting indications.

First, the improvement in the long-term aging resistance is less effective with respect to the short-term one. This may suggest that OMTs influence the low-molecular weight volatilization more than oxidation tendency. The reason could be the higher viscosity of BLS systems, which influences the film renewal during RTFOT. Unfortunately, the viscosities of the mixes are not reported and it is not possible to evaluate this aspect. The OMT quantity is $4 \%$ by weight with respect to bitumen. In the case of simple intercalation, $4 \%$ is a moderate content and presumably does not affect significantly the viscosity value. However, even a small degree of exfoliation, not easily detectable by XRD, may strongly influence such parameter. On the other side, the ineffectiveness observed for long-term aging suggests the absence of both chemical interactions and barrier effect. Since the latter can be significant only in case of exfoliation, this confirms that OLS is mostly intercalated. A possible explanation of the shortterm improvement is that the most volatile components, thanks to their lower molecular weight and steric hindrance, are the ones that mostly intercalate in the LS interlayers. This should reduce their evaporation during RTFOT. Modified and unmodified bitumens behave in a similar manner from the qualitative point of view and the base bitumen curves always remain above those of modified bitumens. With regard to the evaporation of saturates, there is a recent paper that evaluated the volatile organic compound emission from bituminous materials by pyrolysis interfaced with mass spectrometry [59]. After mixing with LS, the bitumen samples were subjected to two nonconventional artificial aging procedures. In the first one, the samples were placed in a vacuum oven at $180^{\circ} \mathrm{C}$ for 8 hours. Due to the absence of oxygen, aging is supposedly imputable only to volatile loss and not to oxidation. The second aging, was similar, but the samples were placed in a draft oven to have an oxidizing atmosphere. The volatile release was measured during a temperature ramp from 50 to $230^{\circ} \mathrm{C}$. In both cases, as expected, the released volatile organic compounds were mainly saturates and the emissions were significantly reduced in the presence of OMMT. Whether this is due to interactions between clay and saturates or a labyrinth effect is debatable, but the result is nonetheless interesting.

Going back to Figures 2 and 3, they show how AI strongly depends on the test temperature (or frequency). This is another reason for possible artefacts and misinterpretation of artificial aging. The choice of the test temperature may strongly influence the conclusions. Therefore, while evaluating the aging performances it is preferable to compare more than one $\mathrm{AI}$ and/or perform the tests in different operating conditions. In the same paper, there is another interesting experimental data: the XRD spectra of the modified bitumens remain almost unchanged after the two artificial agings. This means that the dispersion of the layered silicates does not change significantly during the aging procedure, even if the latter probably modifies the asphaltene cluster size.

Zare-Shahabadi et al. $[60,61]$ provided another example showing the effect of organomodification on the nanocomposite structure, by using a bentonite (BT) and the corresponding organomodified bentonite (OBT). The XRD patterns indicate that the BT-reinforced bitumen has an intercalated structure, while the OBT-reinforced bitumen has an exfoliated structure. Bitumens were subjected to RTFOT and PAV and then characterized by a bending beam rheometer. After aging, both BT- and OBT-modified bitumens yielded lower stiffness than the base bitumen and the OBT-modified bitumens showed the lowest stiffness and highest resistance to low temperature cracking. The authors interpret these results as follows: "platelets in the bitumen 


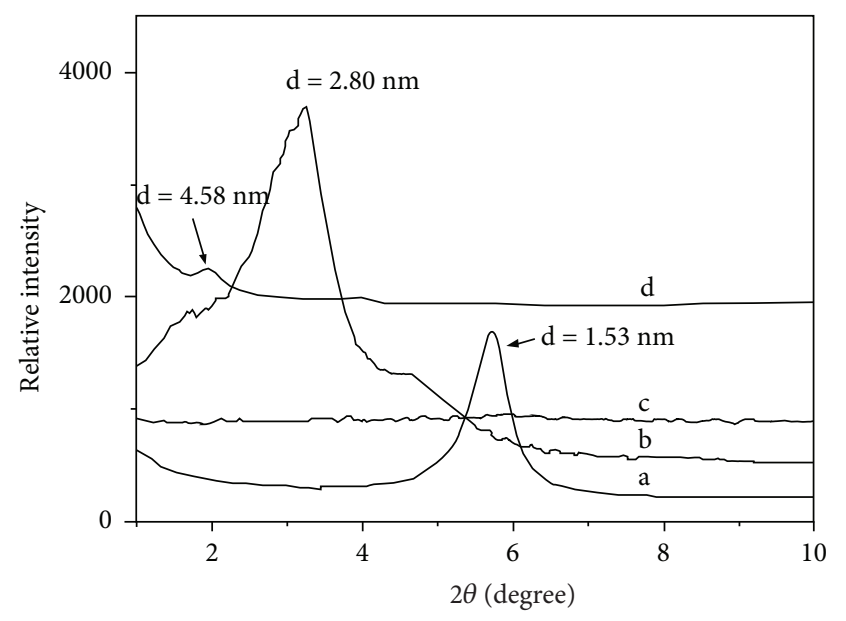

a. $\mathrm{Na}^{+}-\mathrm{MMT}$

b. OMMT

c. $\mathrm{Na}^{+}$-MMT-modified bitumen

d. OMMT-modified bitumen

FIGURE 4: XRD patterns of the LS and modified binders. The native MMT is indicated as $\mathrm{Na}^{+}$-MMT (Figure 2 of [65]).

matrix prevent oxidation of the matrix molecules and volatilization of light oil molecules from the matrix."

Jahromi and Khodaii evaluated the modification with two OMMTs: Cloisite 15A and Nanofill 15 [62, 63]. For both silicates and irrespective of their concentration (up to 7\%), the XRD analysis seems to indicate a complete exfoliation. All materials were tested as unaged, short-, and long-term aged, aging being carried out with the rotating cylindrical aging tester. Samples were subjected to rheological characterization in a frequency sweep performed at different temperatures and used to build master curves assuming thermorheologically simple behaviour. Unfortunately, the master curves are not easy to interpret and do not allow extrapolating the aging effects. The retained penetration and variation of the softening point indicate an antiaging effect increasing with the silicate content and a reduction of the fatigue life in the low-medium temperature range [64].

Zhang et al. [65] modified a bitumen with a MMT and the corresponding OMMT. In the XRD patterns, MMTmodified bitumens have a flat spectrum (Figure 4). This indicates a bad dispersion of the LS, whose peaks are not detected by the instrument. This means that bitumen molecules did not intercalate in the silicate layers. In contrast, in the case of OMMT, the curve raises at low $\vartheta$, thus indicating exfoliation. It is interesting to observe that even though MMT and OMMT have an opposite behaviour in terms of dispersion, both seem to have an antiaging effect. Bitumens were aged using ultraviolet (UV) radiation, then viscosity aging index (VAI) and softening point increment were calculated. The results indicate a beneficial effect of both silicates, but the exfoliated LS is clearly much better than the dispersed one.

Another interesting aspect is the one related to the silicate loading: increasing the filler amount does not necessarily lead to a corresponding increase in binder properties or aging resistance. In the case of an OMMT, loaded up to $12 \%$ by weight, the maximum effect was obtained at $6 \%$, while

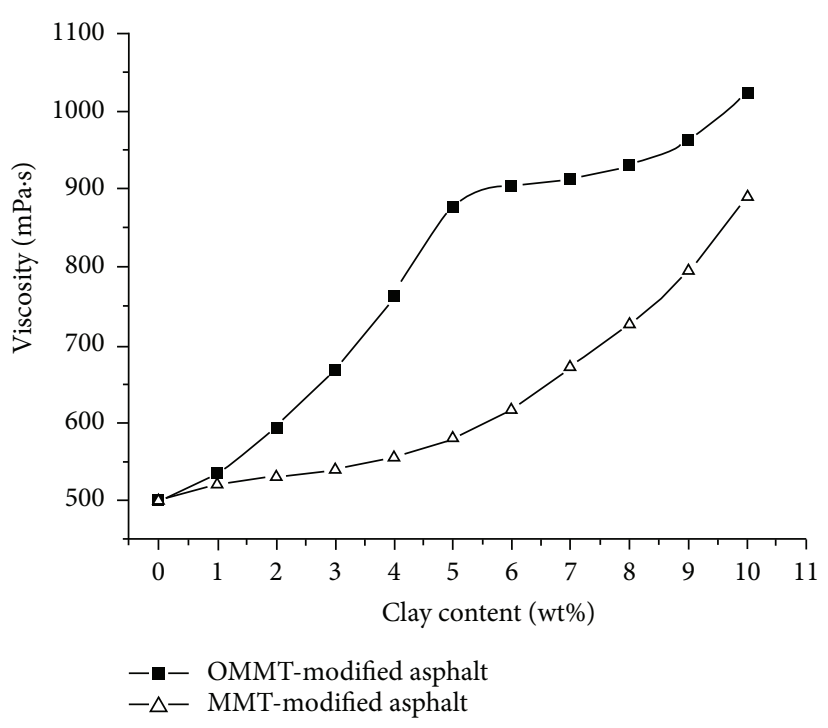

Figure 5: Viscosities at $135^{\circ} \mathrm{C}$ of MMT- and OMMT-modified bitumens as a function of LS content (Figure 3 of [43]). Viscosities were measured with a Brookfield viscometer (Model DV-II+, Brookfield Engineering Inc., USA according to ASTM D4402).

further incrementing the silicate content had no effect on the aging properties [66]. The XRD patterns of the mixes showed an exfoliated/intercalated structure, with the same interlayer distance, independently from the OMMT content. This is quite common in BLS, where the interlayer distance is mainly determined by the affinity between bitumen and silicate, without significant variations related to other parameters, like for example mixing conditions or filler quantity. The more affine molecules migrate into the galleries, thus determining both intercalation and a partial exfoliation. The final interlayer distance depends on the affinity between the two components and the process continues until those "affine" molecules are available. Then, further increasing the OMMT content does not add significant quantities of exfoliated/intercalated stacks since the bitumen molecules more prone to interact are already involved. Therefore, another consequence of the selective interaction between LS and some bitumen molecules is that there is a sort of "maximum degree of modification" corresponding to a maximum antiaging effect or, from a more general point of view, to a maximum obtainable modification of the binder properties. A similar indication of a maximum quantity that can intercalate/exfoliate is shown in Figure 5 [43]. In the plot of viscosity vs. clay content, the MMT and OMMT curves appear very different until 5\% LS. Then, the viscosity of the asphalt modified with OMMT shows a sharp reduction in slope. This suggests that 5\% may correspond to the limit of LS content able to exfoliate/intercalate. Higher clay loadings do not lead to further exfoliation, and the viscosities of the OMMT- and MMT-modified bitumens tend to converge.

Of course, the LS/OLS nature is expected to affect the quality and quantity of the selective interactions between silicate and bitumen properties. Therefore, the importance of chemical interactions between bitumen and LS can be underlined also by comparing the effects of different types 
of silicates. Zhang et al. [49] compared three LS (MMT, expanded vermiculite (EVMT), and rectorite (REC)) and the corresponding OLS obtained with the same organomodifier. Among the pristine LS, only REC formed an intercalated structure. After organic modification, intercalation was obtained for OMMT and OEVMT, and exfoliation was obtained for OREC. Antiaging effects were observed for all tested silicates (modified or not) with OLS, as expected, always performing better than the corresponding LS. Interestingly enough, the antiaging performances were: OEVMT $>$ EVMT $>$ OREC $>$ REC $>$ OMMT $>$ MMT. Moreover, compared with OREC and OMMT, OEVMT has more pronounced improvements in flame retardancy [67]. In other words, intercalated and phase-separated vermiculite performed better that exfoliated and intercalated rectorite. The authors claim that the specific surface area of the three LS parallels this antiaging effect, thus concluding that the thermal aging properties of the binders mainly depend on this parameter, with no significant influence of the nanostructure formed in the modified bitumens. Unfortunately, the paper does not report the specific surface area of the six LS. Whatever is the explanation, the conclusion is that exfoliation itself is not a warranty of better performances when compared to intercalation. This demonstrates that chemical interactions between LS and bitumen may play a fundamental role in these binary systems. The same research group further investigated the properties of the abovementioned binary bitumen LS systems [68-75].

Obviously, the type of organomodifier is a fundamental parameter, since it determines the interactions between bitumen and silicate. Therefore, it is not surprising that the same EVMT, exchanged with cetyltrimethyl ammonium bromide and octadecyl dimethyl benzyl ammonium chloride, gave different results in the aging resistance [76]. A similar comparison of the antiaging properties of bitumens modified with OMMTs obtained by using three different surfactants is the one by $\mathrm{Yu}$ et al. [77]. One of the three OMMT intercalates, while the other two exfoliate. The aging was evaluated in several ways (viscosity, softening point, and ductility), and one of the two exfoliated OMMT gave a better performance, while the other exfoliated OMMT performed slightly better than, if not comparable to, the intercalated one. This is a further confirmation that exfoliation is important, but the nature of the organomodified clay (and thus the chemical component) prevails in determining the antiaging effect.

Mahdi et al. [78] gave another confirmation of the antiaging effect of two OMMTs, whose nature is not specified, for short-term aging (RTFOT). The conventional properties of the binders before and after aging were characterized using retained penetration, increment in softening point, and VAI. The reported graphs suggest that retained penetration and VAI amplify the silicate effect more than the softening point does (Figure 6).

Walters [79] combined the use of Cloisite 30B (a bentonite modified with methyl, tallow, bis-2-hydroxyethyl, and quaternary ammonium salt) and a biochar (also reduced to nanodimensions) and observed an intercalated/exfoliated structure, as well as an antiaging positive effect of the fillers. Other papers describing bitumen-LS mixes, but not the silicate structure or the effects on aging are those by Abdullah et al. [80] and Zamanizadeh et al. [81, 82].

3.2. The Bitumen-Polymer-Layered Silicate Ternary (BPLS) Systems. The two technologies of PMB and PLS, although known for several decades, met only recently. The idea was to transfer the advantages of the second one into the former. The main goal was an improvement in the binder performances, but the main advantage immediately observed concerns increased bitumen/polymer compatibility. Even though somehow unexpected, this is not surprising, because it was already known that LS might be used as compatibilizer agents in polymer blends. This aspect of LS acting as a polymer/bitumen compatibilizer is fully considered in previous works $[83,84]$ and will not be discussed in detail here. We can limit our work to the observation that the compatibilization is related to selective interactions between clay, polymer, and some bitumen molecules. The polymer tends to prefer the aromatic fractions of the bitumen, while the clay probably affords fractions with higher polarity. A preformed PLS nanocomposite is thus able to combine these affinities and widens the spectra of binder molecules thus enabling the polymer to swell.

In the bitumen practice, SBS is by far the most used polymer modifier and SIS (styrene-isoprene-styrene) is the only other thermoplastic elastomer in the market. Among plastomers, poly(ethylene-co-vinyl acetate) (EVA) is the only one currently used as a modifier, while polyolefins are more likely to be considered additives instead of modifiers [83]. Even if covering a higher number of polymers, the bitumen literature reflects the practice and mainly analyses SBS-modified bitumens. Among these, the B/SBS/MMT (OMMT) ternary system is the most studied one. Ternary systems can be prepared in two different ways. The first one consists of the addition of clay and polymer to bitumen as separate entities, while in the second one a preformed PLS is added to the bitumen with the same procedures used for pure polymers. In the literature of bitumen nanocomposites, to our knowledge, transmission electron microscopy (TEM) has been rarely used to investigate the final morphology [82], while indirect information was most likely obtained by X-ray diffractometry.

Ternary systems based on SBS and MMT were evaluated from both the structure and aging point of views. Not surprisingly, the MMT/SBS-modified bitumen was found to form phase-separated structures, while the OMMT/SBS gave intercalated structures $[23,47]$. Aging was evaluated under UV radiation and, with respect to binary bitumen/SBS systems, both VAI and softening point increment showed a decrease due to the introduction of MMT, which was further enhanced while using OMMT. By substituting MMT with EVMT, the situation was similar, since the pristine LS gave phase-separated structures, while OEVMT exfoliated [85]. Similar to the previous case are also the conclusions after artificial aging: the aging resistance increases in the presence of EVMT, the effect being more pronounced when using OEVMT.

Farias et al. [86] evaluated a few rheological properties, but did not investigate the structure and aging resistance of the materials. Golestani et al. [87] showed that the structure 


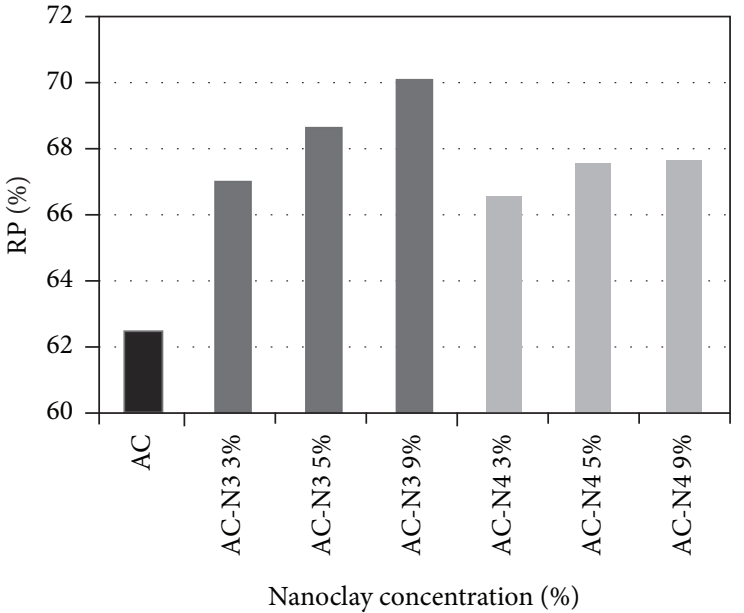

(a)

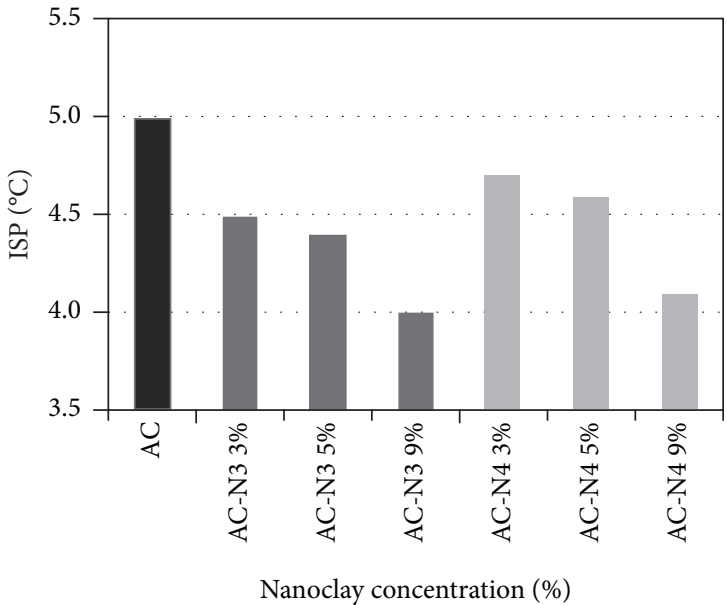

(b)

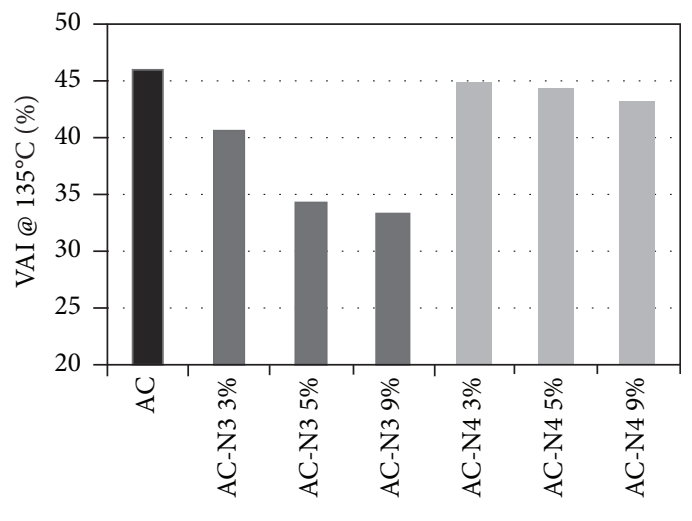

Nanoclay concentration (\%)

(c)

FIGURE 6: Effect of LS concentration on aging properties: (a) retained penetration, (b) increment in softening point, and (c) viscosity aging index at $135^{\circ} \mathrm{C}$. The two LS are indicated as AC-N3 and AC-N4 (Figure 2 of [78]).

of the nanocomposite may depend on the polymer architecture: with the same bitumen and OMMT, a linear SBS gave exfoliation, whereas a branched SBS gave intercalation. The performance of this ternary system was evaluated in another work by the same authors [88]. In contrast, Polacco et al. [89] found intercalation for a linear SBS. These discrepancies are not surprising, since the structure of the ternary system strongly depends on the characteristics of the three ingredients; therefore, changing a single component may completely change the result and a generalization is almost impossible.

Jasso et al. [90] mainly concentrated their work on the rheological properties of bitumens modified with SBS, OMMT, and a sulphur-based SBS-bitumen compatibilizer and observed that the organoclay had a positive influence specifically on service temperatures. The performances and PG grades were evaluated after artificial aging and even if the authors do not define aging indexes, they show a worsening of the maximum service temperatures of the binders subjected to RTFO. This is generically attributed to "spotted interactions between the SBS and the organoclay and the SBS and Additive A, i.e., by thermooxidation degradation or insufficient dispersion of organoclays into asphalt binders"
[91]. It is worth noting that this is the only paper where a worsening in aging resistance related to the presence of LS is reported.

Yu et al. [92] prepared ternary systems using MMT and OMMT, then they evaluated the nanocomposite structure and the resistance to aging. Based on the XRD spectra, MMT gave an intercalated structure, with a significant increase in the lamellar interlayer spacing, while OMMT gave exfoliation. With regard to aging, it is interesting to report the three graphs presented in the paper, relative to shortand long-term tests. Figures 7 and 8 show the VAI and variation of the softening point, respectively.

The softening point increases after RTFOT, but a reduction is observed after PAV. This softening point reduction in the presence of SBS is related to the abovementioned degradation, with a decrease of polymer molecular weight. During aging, there are two counteracting effects. The first one is the loss of volatiles and the increase of asphaltenes in bitumen, that lead to higher viscosity and softening point. The second one is a degradation of SBS that has an opposite effect. In the case of viscosity, the first effect prevails in both RTFOT and PAV. In contrast, for the softening point the hardening of 


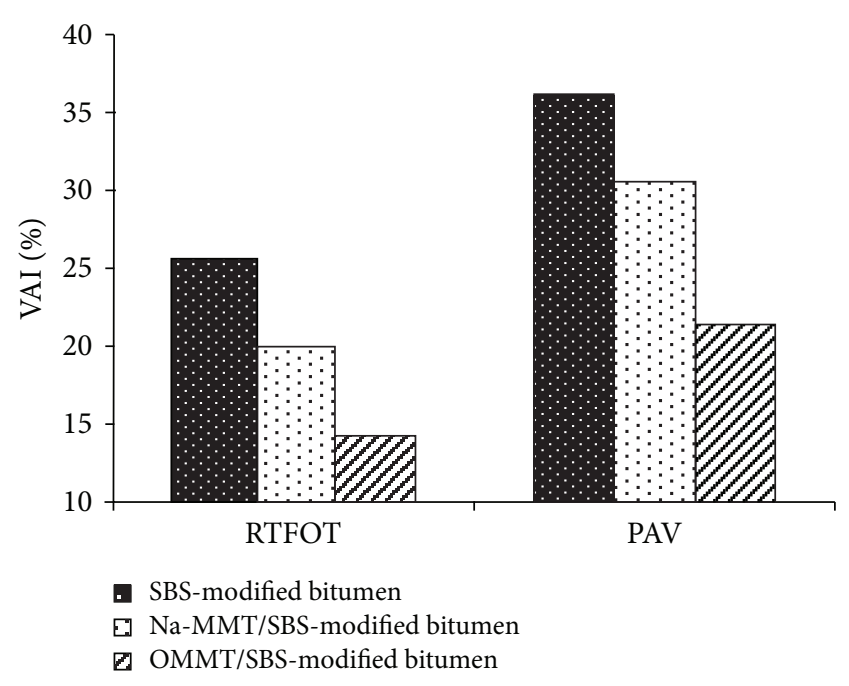

Figure 7: VAI of modified bitumen after RTFOT and PAV (Figure 8 of [92]).

bitumen exceeded the influence of SBS degradation after RTFOT, while the result is reversed after PAV. Eventually, Figure 9 shows retained ductility.

From a numerical point of view, for ductility the situation is intermediate between the case of VAI and softening point, with aging index after PAV much smaller than that evaluated after RTFOT. These three graphs represent an interesting example of the potential difficulties related with interpretation of the results in aging tests, especially in the presence of unsaturated polymers like SBS. Nevertheless, we can underline that the aging indexes of the three samples follow the same qualitative trend irrespective of the measured quantity. The SBS degradation explains also the "anomaly" reported by Tang et al. [93] who found that the softening point of the B/SBS/MMT decreased after RTFOT, in contrast with that of the base bitumen. The degradation of SBS is mainly due to the presence of a $\mathrm{C}=\mathrm{C}$ double bond in the repeating unit and may already start while processing the polymer to produce the SBS/LS nanocomposites subsequently used to modify the bitumen. As an example, we can mention the paper by Ouyang et al. [94] who prepared BPLS ternary systems by using a kaolinite and measured the SBS molecular weight distributions after processing at different temperatures (Figure 10).

Still for the B/SBS/OMMT system, Galooyak et al. [95] found an exfoliated structure and showed that the LS allows both improvement in storage stability and in short-term aging resistance. The data indicate an improvement related with the LS content (Table 1). Similar results were found when comparing linear and branched SBS [96].

Remaining on SBS as a polymer, there are a few other papers with different LS. Wang et al. [97] used an OBT and after RTFOT report an improvement of rheological properties in comparison with SBS-modified bitumen. Khodary [98] gives an accurate chemical composition of the used LS, but does not specify its name and/or type and says that fatigue life of the bitumen/SBS/LS is higher than unmodified bitumen.

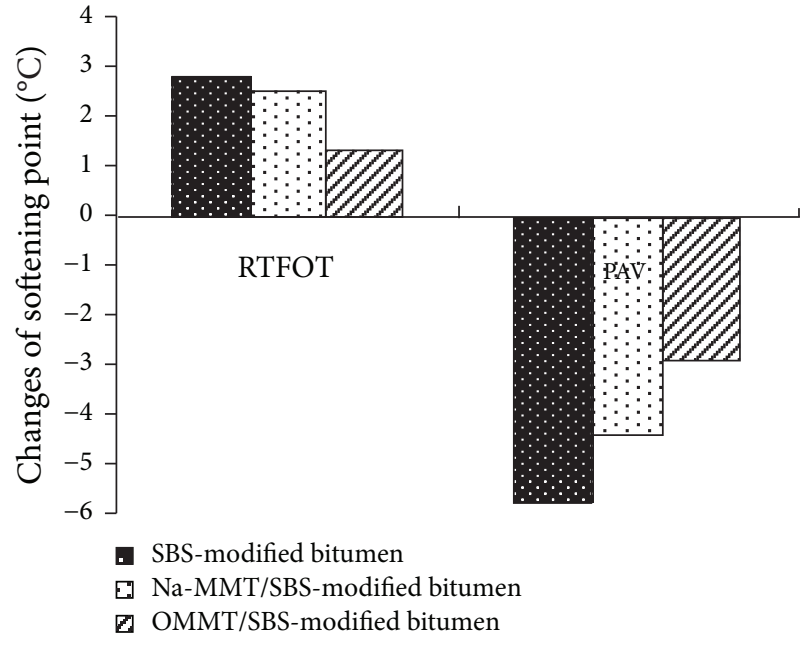

Figure 8: Changes of softening point of modified bitumen after RTFOT and PAV (Figure 9 of [92]).

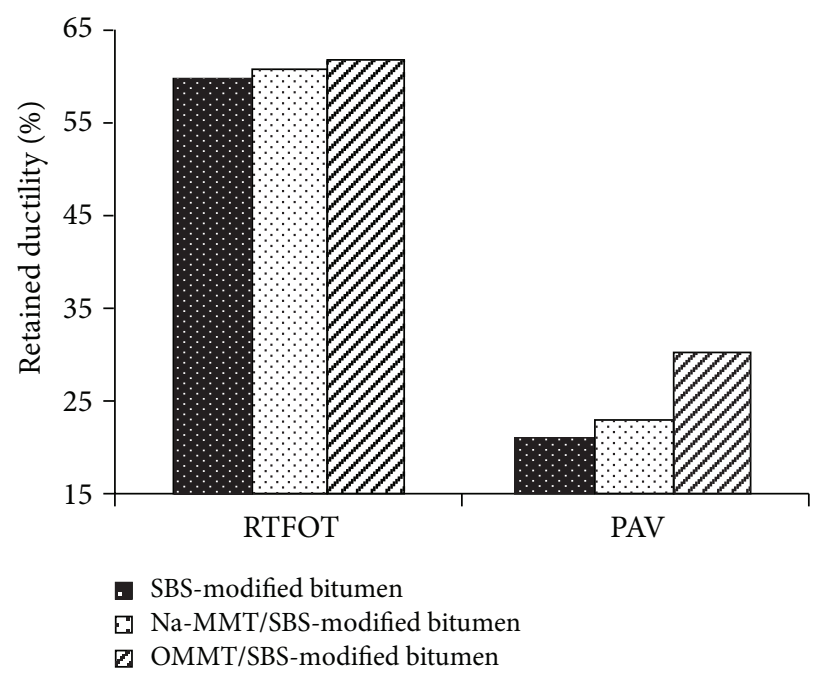

FIGURE 9: Retained ductility of modified bitumen after RTFOT and PAV (Figure 10 of [92]).

For polymers different from SBS, there are only a few papers available. In the case of polyolefins, like polyethylene and polypropylene the ternary mixes were prepared, but their aging resistance was not evaluated [99-103]. This is not surprising since polyolefins are not compatible with bitumens and the binders show storage instability and low performances. The LS enhances the bitumen/olefin compatibility a little bit, but not enough to justify their use in practical applications.

Sureshkumar et al. [104, 105] studied the structure and rheological properties of ternary systems prepared with poly(ethylene-co-vinyl acetate), but did not evaluate aging resistance. Styrene-ethylene-butylene-styrene block copolymer (SEBS) was used together with an OMMT [106] and with kaolinite [107]. In the first case, exfoliation of the LS was obtained, while in the second one, the authors mainly focused on storage stability. Recently, binders modified with 


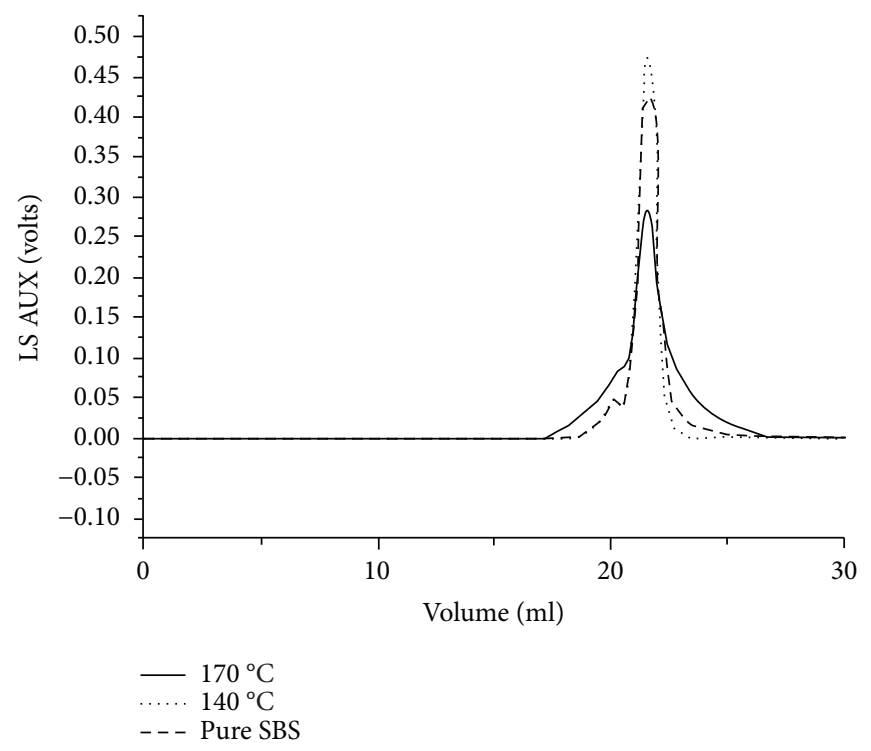

FIGURE 10: Variations of molecular weight distribution of SBS at different mixing temperatures (Figure 3 of [94]).

TABLE 1: Effect of OMMT on aging properties of SBS-modified bitumen in RTFO test (Table 10 of [95]).

\begin{tabular}{lccc}
\hline $\begin{array}{l}\text { SBS/OMMT } \\
(\mathrm{wt} / \mathrm{wt})\end{array}$ & $\begin{array}{c}\text { Retained penetration } \\
\text { at } 25^{\circ} \mathrm{C} \\
(\%)\end{array}$ & $\begin{array}{c}\text { Softening } \\
\text { point }(\mathrm{SP}) \\
\left({ }^{\circ} \mathrm{C}\right)\end{array}$ & $\begin{array}{c}\left(\mathrm{SP}_{\mathrm{ag}}-\mathrm{SP}_{\text {or }}\right) \\
\left({ }^{\circ} \mathrm{C}\right)\end{array}$ \\
\hline $0 / 0$ & 65.9 & 52 & 4.8 \\
$100 / 0$ & 68.5 & 64.8 & 2.3 \\
$100 / 35$ & 71.7 & 66.8 & 0.8 \\
$100 / 50$ & 72.2 & 67.9 & 0.4 \\
$100 / 65$ & 73.3 & 69.8 & -0.4 \\
\hline
\end{tabular}

SEBS and OMMT were found to be more susceptible to aging and this was attributed to a restricted swelling of SEBS in bitumen, due to the clay [108].

Styrene butadiene rubber (SBR) and palygorskite with and without organomodification were subjected to RTFOT. Then, complex modulus, phase angle, and rutting factors before and after aging were compared [109]. The reported values are not of immediate interpretation and leave some doubts about the effect of the LS and the differences between the two palygorskites. For both binary and ternary systems, it is not possible to identify a univocal trend of the aging indexes with type or content of clay. We can just underline that in most cases the presence of the clay reduces the percentage variation of the measured parameters. Santagata et al. [110] mixed bitumen with polyisoprene and OMMT and subjected the materials to RTFOT, showing a positive influence of the LS. Yao et al. [111] present a rather detailed study where short- and long-term aging properties of nanomodified bitumen are evaluated. The LS is an OMMT, but unfortunately, it is not clear which polymer was used. A final mention is necessary for three works by Ortega et al. [112-114] who mixed bitumen with OMMT and polymeric methylene diphenyl diisocyanate. The authors accurately evaluated the effects of shear processing and modification sequence on the thermomechanical properties of such composites. The diisocyanate is able to react with carboxylic and amine functionalities, and after blending, it creates a chemical network that includes a polymer and asphaltenes. These works follow quite a long list of previous works based on the binary bitumen/methylene diphenyl diisocyanate system (e.g., see [115-120].

\section{Layered Double Hydroxides (LDH)}

Layered double hydroxides are a class of ionic lamellar compounds made up of positively charged brucite-like layers of organic-inorganic or inorganic-inorganic nanomaterials. Compared to clays, LDHs are less prone to delamination due to strong interlayer interactions between the sheets and often extensive interlamellar hydrogen bonding networks lead to a tight stacking of the lamellae [121]. The research on LDHs is rapidly growing and the known applications cross many disciplines, such as in the study of catalysts, catalyst precursors, anion exchangers, $\mathrm{CO}_{2}$ absorbents, bioactive nanocomposites, and electroactive and photoactive materials. In recent years, polymer/LDH nanocomposites have attracted interest for applications in organoceramics, biomaterials, and electrical and mechanical materials. As for the case of LS, the performance of polymer/LDH nanocomposites strongly depends on the degree of dispersion (intercalation or exfoliation) of $\mathrm{LDH}$ layers in the polymeric matrix. As already mentioned, due to their high charge density ( $300 \mathrm{meq} / 100 \mathrm{~g}), \mathrm{LDH}$ layers are characterized by a strong interlayer electrostatic interaction that makes exfoliation difficult. Therefore, like for the case of LS, the intercalation of macromolecules into the $\mathrm{LDH}$ lamellae requires organic modification (thus producing OLDH) to expand the basal spacing. This reluctance to exfoliation is not the best premise for the use as bitumen additives with antiaging properties. Nevertheless, we already observed that exfoliation is not essential since the main point is obtaining a high level 
TABLE 2: Aging parameters of the LDH-modified bitumen (Table 1 of [126]).

\begin{tabular}{lcccc}
\hline \multirow{2}{*}{ Parameter } & \multicolumn{4}{c}{ Mass percentage of LDH } \\
& 0 & 1 & 3 & 5 \\
\hline Unaged viscosity $\left(135^{\circ} \mathrm{C}, \mathrm{Pa}\right)$ & 0.33 & 0.38 & 0.48 & 0.49 \\
Aged viscosity $\left(135^{\circ} \mathrm{C}, \mathrm{Pa}\right)$ & 14.1 & 4.20 & 2.40 & 2.10 \\
VAI $(\%)$ & 41.7 & 9.90 & 4.00 & 3.30 \\
Unaged SP $\left({ }^{\circ} \mathrm{C}\right)$ & 46.3 & 46.8 & 47.0 & 47.1 \\
Aged SP $\left({ }^{\circ} \mathrm{C}\right)$ & 84.2 & 83.4 & 79.9 & 79.0 \\
$\mathrm{SP}_{\mathrm{ag}}-\mathrm{SP}_{\text {or }}\left({ }^{\circ} \mathrm{C}\right)$ & 37.9 & 36.6 & 32.9 & 31.9 \\
\hline
\end{tabular}

of binder/filler interactions. Therefore, exactly as it was for LS, $\mathrm{LDH}$ can also be chemically modified to increase the interactions with bitumen molecules. Since LDH itself possesses UVshielding properties, the modification with an organic UV absorber is often used to increment this property. This explains why the literature concerning $\mathrm{LDH}$ and bitumen is almost completely focused on UV resistance, with only a few exceptions, like reduction in emission of organic volatile compounds $[122,123]$ or use as a deicing additive $[124,125]$. Shi et al. [126] used a lab-prepared unmodified LDH and correlated the UV-shielding properties of the material with chemical composition, structure, and morphology (particle size and thickness). A significant improvement in UV resistance of bitumens modified with the LDH is reported (Table 2).

The research group that published more papers dealing with bitumen and LDHs is that of $\mathrm{Xu}$ et al. who examined LDH either unmodified or modified with different organic compounds such as salicylic acid [127], 2-hydroxybenzoic acid and 2-hydroxy-4-methoxybenzophenone-5-sulfonic acid [128], sodium dodecyl sulphate and sodium dodecyl sulfonate [129-131], and Irganox 1010 (a commercial antioxidant) [132], as well as compounds doped with zinc [133]. All the papers are similar, with analysis of the interlayer distances through XRD and evaluation of aging indexes based on viscosity, softening point, and/or rheology. A common characteristic is that the all LDHs intercalate, with an interlayer distance that increases with organic modification and does not change significantly after bitumen addition. Nevertheless, in all cases, the LDH improves the UV resistance of the binder and OLDH works even better. In a few cases, in addition to UV resistance, the aging resistance is reported to increase also after artificial aging [131, 134, 135].

The other papers published on this topic are similar, with the main difference being the type of organomodifier $[31,136-142]$. Finally, the OLDHs are successfully used in combination with SBS [143-145] and crumb rubber [146].

\section{Conclusions}

The literature concerning the use of nanoadditives in bitumen is relatively young and shows an increasing interest of the scientific community, with particular attention to bitumen durability. Given the absence of a normative for artificial aging of bitumen modified with inorganic fillers, the first problem is the lack of univocal procedures that makes it difficult to compare data coming from different laboratories.
The choice of the operating conditions is a fundamental parameter that in many cases may lead to artefacts and misinterpretation of the experimental data. Nevertheless, the available literature almost unanimously reports a positive effect of nanoadditives on bitumen durability. Therefore, at least from a qualitative point of view, we know that these materials may be used for this purpose.

With regard to the involved mechanisms, they are probably both of physical and chemical nature. The classical physical mechanism is the barrier effect that inorganic particles exert against permeation of low molecular weight molecules such as oxygen. Even if often invoked as the main reason in lowering oxidation kinetic, in the case of LS the real importance of this mechanism has not been demonstrated yet. The physical barrier is coherent with the observation that exfoliation usually works better than intercalation. However, this correspondence between intercalation and exfoliation is true only for specific LS. When comparing different LS, it may happen that, for the same bitumen, intercalated LS works better than exfoliated ones. The reasons could be a different specific interfacial area and/or chemical-physical interactions between bitumen and nanomaterials. These interactions lead to irreversible adsorption of asphaltenes and resins, through molecular association or pore adsorption, thus reducing their reactivity toward oxygen. The LS may subtract bitumen molecules from oxidation either creating chemical bonds with their functional groups or hiding them in the interlayer galleries. These aspects are still to be clarified and merit investigation since they may help improving the filler performances. Another interesting aspect is that exfoliation (when possible) may be obtained only for a limited quantity of LS. In other words, there is a maximum load of LS that can exfoliate/intercalate. For higher loadings, the exceeding LS will give a low contribution to the binder properties.

Since each bitumen has its own composition and chemical structure, each specific filler-bitumen couple has its own behaviour and a generalization of the experimental results is not possible. This is particularly important in the case of organomodified nanosized fillers, since the choice of the organomodifier influences the entity of the antiaging effect.

Finally, we would like to underline a couple of important aspects that have been deeply analysed in the PLS literature, but but have not yet received attention in the case of BLS and BPLS systems. The first one is that the operating conditions adopted during mixing, mainly temperature and shear stress, may influence the LS interlayer distances. The reason is that the organomodifiers are subjected to degradation or structural modifications. A classic example is the case of Cloisite $30 \mathrm{~B}$ that often undergoes a d-spacing collapse during PLS preparation. This phenomenon has been long debated and could be due to thermal degradation of the organic modifier or, more probably, to a reversible rearrangement of the alkyl chains of the clay modifier [147]. Whatever is the mechanism, a reduction of the interlayer basal spacing diminishes the chances of other molecules to enter the galleries. Therefore, the same LS/bitumen binary system may give different results depending on the mixing conditions. If the latter are too aggressive, they can alter the original LS structure and reduce its intercalation/exfoliation capacity. 
Second, the addition sequence is important in the case of ternary systems. There are many possibilities, like adding LS and a polymer contemporary, or adding first the polymer and then the clay or vice versa, or premix LS and a polymer, then add a PLS to bitumen. These procedures are not equivalent and may significantly influence the result.

As a general conclusion, nanomaterials have been demonstrated to be promising and are attracting increasing interest in the industrial and scientific communities, but their use in bituminous mixes still has many aspects to be clarified and optimized.

\section{Abbreviations}

$\begin{array}{ll}\text { AI: } & \text { Aging index } \\ \text { BLS: } & \text { Bitumen/layered silicates } \\ \text { BPLS: } & \text { Bitumen/polymer/layered silicates } \\ \text { BT: } & \text { Bentonite } \\ \text { CEC: } & \text { Cation-exchange capacity } \\ \text { EVA: } & \text { Poly(ethylene-co-vinyl acetate) } \\ \text { EVMT: } & \text { Expanded vermiculite } \\ \text { FTIR: } & \text { Fourier transform infrared } \\ \text { HL: } & \text { Hydrated lime } \\ \text { LDH: } & \text { Layered double hydroxides } \\ \text { LS: } & \text { Layered silicates } \\ \text { MMT: } & \text { Montmorillonite } \\ \text { nHL: } & \text { Nanohydrated lime } \\ \text { OBT: } & \text { Organomodified bentonite } \\ \text { OEVMT: } & \text { Organomodified expanded vermiculite } \\ \text { OLDH: } & \text { Organomodified layered double hydroxides } \\ \text { OLS: } & \text { Organomodified layered silicates } \\ \text { OMMT: } & \text { Organomodified montmorillonite } \\ \text { OREC: } & \text { Organomodified rectorite } \\ \text { PAV: } & \text { Pressure aging vessel } \\ \text { PLS: } & \text { Polymer layered silicates } \\ \text { PMB: } & \text { Polymer-modified bitumen } \\ \text { REC: } & \text { Rectorite } \\ \text { RTFOT: } & \text { Rolling thin film oven test } \\ \text { SBR: } & \text { Styrene butadiene rubber } \\ \text { SBS: } & \text { Styrene-butadiene-styrene block copolymer } \\ \text { SEBS: } & \text { Styrene-ethylene-butylene-styrene block } \\ & \text { copolymer } \\ \text { SIS: } & \text { Styrene-isoprene-styrene block copolymer } \\ \text { UV: } & \text { Ultraviolet } \\ \text { VAI: } & \text { Viscosity aging index } \\ \text { XRD: } & \text { X-ray diffraction. } \\ & \end{array}$

\section{Conflicts of Interest}

The authors declare that there is no conflict of interest regarding the publication of this paper.

\section{References}

[1] J. C. Petersen, A Review of the Fundamentals of Asphalt Oxidation: Chemical, Physicochemical, Physical Property, and Durability Relationships, Transportation Research Board, Washington, D.C., USA, 2009, November 2016, https:// www.nap.edu/catalog/23002.
[2] G. D. Airey, "State of the art report on ageing test methods for bituminous pavement materials," International Journal of Pavement Engineering, vol. 4, no. 3, pp. 165-176, 2003.

[3] D. Lesueur, A. Teixeira, M. M. Lázaro, D. Andaluz, and A. Ruiz, "A simple test method in order to assess the effect of mineral fillers on bitumen ageing," Construction and Building Materials, vol. 117, pp. 182-189, 2016.

[4] F. Migliori and J.-F. Corté, "Comparative study of RTFOT and PAV aging simulation laboratory tests," Transportation Research Record, vol. 1638, pp. 56-63, 1998.

[5] B. Hofko and M. Hospodka, "Rolling thin film oven test and pressure aging vessel conditioning parameters," Transportation Research Record, vol. 2574, pp. 111-116, 2016.

[6] R. Moraes and H. Bahia, "Effect of mineral fillers on the oxidative aging of asphalt binders," Transportation Research Record, vol. 2506, pp. 19-31, 2015.

[7] J. C. Petersen, R. E. Robertson, J. F. Branthaver et al., Binder Characterization and Evaluation Volume 4: Test Methods, National Academy of Sciences, Washington, D.C., USA, 1994.

[8] R. C. Meininger, Effects of Aggregates and Mineral Fillers on Asphalt Mixture Performance, STP1147-EB, ASTM International, West Conshohocken, PA, USA, 1992.

[9] L. W. Corbett, "Composition of asphalt based on generic fractionation, using solvent deasphaltening, elutionadsorption chromatography, and densimetric characterization," Analytical Chemistry, vol. 41, no. 4, pp. 576-579, 1969.

[10] J. C. Petersen, "Quantitative method using differential infrared spectrometry for the determination of compound types absorbing in the carbonyl region in asphalts," Analytical Chemistry, vol. 47, no. 1, pp. 112-117, 1975.

[11] B. K. Wilt, W. T. Welch, and J. G. Rankin, "Determination of asphaltenes in petroleum crude oils by Fourier transform infrared spectroscopy," Energy \& Fuels, vol. 12, no. 5, pp. 1008-1012, 1998.

[12] S. Colaiocco and M. Farrera, "Determination of asphaltene content in crude oil by attenuated total reflectance infrared spectroscopy and neural networks algorithms," Process Analytical Chemistrty, vol. 8, no. 1, pp. 23-26, 2002.

[13] X. Lu and U. Isacsson, "Effect of ageing on bitumen chemistry and rheology," Construction and Building Materials, vol. 16, no. 1, pp. 15-22, 2002.

[14] R. Karlsson and U. Isacsson, "Application of FTIR-ATR to characterization of bitumen rejuvenator diffusion," Journal of Materials in Civil Engineering, vol. 15, no. 2, pp. 157-165, 2003.

[15] B. F. Bowers, B. Huang, X. Shu, and B. C. Miller, "Investigation of reclaimed asphalt pavement blending efficiency through GPC and FTIR," Construction and Building Materials, vol. 50, pp. 517-523, 2014.

[16] Z. Feng, H. Bian, X. Li, and J. Yu, "FTIR analysis of UV aging on bitumen and its fractions," Materials and Structures, vol. 49, no. 4, pp. 1381-1389, 2016.

[17] M. N. Siddiqui and M. F. Ali, "Studies on the aging behavior of the Arabian asphalts," Fuel, vol. 78, no. 9, pp. 1005-1015, 1999.

[18] M. Le Guern, E. Chailleux, F. Farcas, S. Dreessen, and I. Mabille, "Physico-chemical analysis of five hard bitumens: identification of chemical species and molecular organization 
before and after artificial aging," Fuel, vol. 89, no. 11, pp. 3330-3339, 2010.

[19] L. Sun, Y. Wang, and Y. Zhang, "Aging mechanism and effective recycling ratio of SBS modified asphalt," Construction and Building Materials, vol. 70, pp. 26-35, 2014.

[20] Y. Zhao, F. Gu, J. Xu, and J. Jin, "Analysis of aging mechanism of SBS polymer modified asphalt based on Fourier transform infrared spectrum," Journal of Wuhan University of Technology-Material Science Edition, vol. 25, no. 6, pp. 1047-1052, 2010.

[21] M. E. Abdullah, K. A. Zamhari, R. Buhari, M. N. Nayan, and H. Mohd Rosli, "Short term and long term aging effects of asphalt binder modified with montmorillonite," Key Engineering Materials, vol. 594-595, pp. 996-1002, 2013.

[22] H. Zhang, C. Zhu, J. Yu, B. Tan, and C. Shi, "Effect of nanozinc oxide on ultraviolet aging properties of bitumen with 60/ 80 penetration grade," Materials and Structures, vol. 48, no. 10, pp. 3249-3257, 2015.

[23] H. Zhang, J. Yu, H. Wang, and L. Xue, "Investigation of microstructures and ultraviolet aging properties of organomontmorillonite/SBS modified bitumen," Materials Chemistry and Physics, vol. 129, no. 3, pp. 769-776, 2011.

[24] J. Lamontagne, "Comparison by Fourier transform infrared (FTIR) spectroscopy of different ageing techniques: application to road bitumens," Fuel, vol. 80, no. 4, pp. 483-488, 2001.

[25] V. Mouillet, J. Lamontagne, F. Durrieu, J.-P. Planche, and L. Lapalu, "Infrared microscopy investigation of oxidation and phase evolution in bitumen modified with polymers," Fuel, vol. 87, no. 7, pp. 1270-1280, 2008.

[26] P. Cong, P. Xu, and S. Chen, "Effects of carbon black on the anti aging, rheological and conductive properties of SBS/ asphalt/carbon black composites," Construction and Building Materials, vol. 52, pp. 306-313, 2014.

[27] P. Marsac, N. Piérard, L. Porot et al., "Potential and limits of FTIR methods for reclaimed asphalt characterisation," Materials and Structures, vol. 47, no. 8, pp. 1273-1286, 2014.

[28] M. N. Siddiqui, M. F. Ali, and J. Shirokoff, "Use of X-ray diffraction in assessing the aging pattern of asphalt fractions," Fuel, vol. 81, no. 1, pp. 51-58, 2002.

[29] M. N. Siddiqui and M. F. Ali, "Investigation of chemical transformations by NMR and GPC during the laboratory aging of Arabian asphalt," Fuel, vol. 78, no. 12, pp. 14071416, 1999.

[30] D. Lesueur, "The colloidal structure of bitumen: consequences on the rheology and on the mechanisms of bitumen modification," Advances in Colloid and Interface Science, vol. 145, no. 1-2, pp. 42-82, 2009.

[31] H. Wu, L. Li, J. Yu, S. Xu, and D. Xie, "Effect of layered double hydroxides on ultraviolet aging properties of different bitumens," Construction and Building Materials, vol. 111, pp. 565-570, 2016.

[32] D. Lesueur, J. Petit, and H.-J. Ritter, "The mechanisms of hydrated lime modification of asphalt mixtures: a state-ofthe-art review," Road Materials and Pavement Design, vol. 14, no. 1, pp. 1-16, 2013.

[33] J. Shen, B.-S. Huang, X. Shu, and B.-M. Tang, "Size effect of sub nano-scaled hydrated lime on selected properties of HMA," International Journal of Pavement Research and Technology, vol. 4, pp. 252-257, 2011.

[34] J. Cheng, J. Shen, and F. Xiao, "Moisture susceptibility of warm-mix asphalt mixtures containing nanosized hydrated lime," Journal of Materials in Civil Engineering, vol. 23, no. 11, pp. 1552-1559, 2011.

[35] A. Kavussi and P. Barghabani, "The influence of nano materials on moisture resistance of asphalt mixes," Study of Civil Engineering and Architecture, vol. 3, 2014, http://dpijournals.com/index.php/SCEA/article/view/1153.

[36] A. Kavussi and P. Barghabany, "Investigating fatigue behavior of nanoclay and nano hydrated lime modified bitumen using LAS test," Journal of Materials in Civil Engineering, vol. 28, no. 3, article 04015136, 2016.

[37] F. Khodary, M. S. A. El-sadek, and H. El-Sheshtawy, "Mechanical properties of modified asphalt concrete mixtures using $\mathrm{Ca}(\mathrm{Oh}) 2$ nanoparticles," International Journal of Civil Engineering and Technology (IJCIET), vol. 5, pp. 6168, 2014.

[38] H. Yao, Q. Dai, and Z. You, "Chemo-physical analysis and molecular dynamics (MD) simulation of moisture susceptibility of nano hydrated lime modified asphalt mixtures," Construction and Building Materials, vol. 101, pp. 536-547, 2015.

[39] A. Diab, Z. You, Z. Hossain, and M. Zaman, "Moisture susceptibility evaluation of nanosize hydrated limemodified asphalt-aggregate systems based on surface free energy concept," Transportation Research Record: Journal of the Transportation Research Board, vol. 2446, no. 1, pp. 52-59, 2014.

[40] S. Sinha Ray and M. Okamoto, "Polymer/layered silicate nanocomposites: a review from preparation to processing," Progress in Polymer Science, vol. 28, no. 11, pp. 1539-1641, 2003.

[41] R. Li, F. Xiao, S. Amirkhanian, Z. You, and J. Huang, "Developments of nano materials and technologies on asphalt materials-a review," Construction and Building Materials, vol. 143, pp. 633-648, 2017.

[42] F. C. G. Martinho and J. P. S. Farinha, "An overview of the use of nanoclay modified bitumen in asphalt mixtures for enhanced flexible pavement performances," Road Materials and Pavement Design, pp. 1-31, 2017.

[43] J. Yu, X. Zeng, S. Wu, L. Wang, and G. Liu, "Preparation and properties of montmorillonite modified asphalts," Materials Science and Engineering A, vol. 447, no. 1-2, pp. 233-238, 2007.

[44] G. Liu, S. Wu, M. . de Ven, J. Yu, and A. Molenaar, "Influence of sodium and organo-montmorillonites on the properties of bitumen," Applied Clay Science, vol. 49, no. 1-2, pp. 69-73, 2010.

[45] Z. You, J. Mills-Beale, J. M. Foley et al., "Nanoclay-modified asphalt materials: preparation and characterization," Construction and Building Materials, vol. 25, no. 2, pp. 10721078, 2011.

[46] M. D. Nazzal, S. Kaya, T. Gunay, and P. Ahmedzade, "Fundamental characterization of asphalt clay nanocomposites," Journal of Nanomechanics and Micromechanics, vol. 3, no. 1, pp. 1-8, 2013.

[47] H. Zhang, J. Yu, and S. Wu, "Effect of montmorillonite organic modification on ultraviolet aging properties of SBS modified bitumen," Construction and Building Materials, vol. 27, no. 1, pp. 553-559, 2012.

[48] Z. P. Zhang, Y. Wen, J. Z. Pei, and S. F. Chen, "Modification of asphalt by montmorillonite," Applied Mechanics and Materials, vol. 84-85, pp. 662-666, 2011. 
[49] H. L. Zhang, B. Y. Tan, H. B. Xu, and K. Z. Yan, "Microstructures and thermal aging properties of layered silicate modified bitumens," Petroleum Science and Technology, vol. 32, no. 14, pp. 1697-1703, 2014.

[50] F. Laoutid, L. Bonnaud, M. Alexandre, J.-M. Lopez-Cuesta, and P. Dubois, "New prospects in flame retardant polymer materials: from fundamentals to nanocomposites," Materials Science \& Engineering R: Reports, vol. 63, no. 3, pp. 100-125, 2009.

[51] P. Kiliaris and C. D. Papaspyrides, "Polymer/layered silicate (clay) nanocomposites: an overview of flame retardancy," Progress in Polymer Science, vol. 35, no. 7, pp. 902-958, 2010.

[52] H. Ma, P. Song, and Z. Fang, "Flame retarded polymer nanocomposites: development, trend and future perspective," Science China. Chemistry, vol. 54, no. 2, pp. 302-313, 2011.

[53] A. B. Morgan, "Flame retarded polymer layered silicate nanocomposites: a review of commercial and open literature systems," Polymers for Advanced Technologies, vol. 17, no. 4, pp. 206-217, 2006.

[54] J. W. Gilman, "Flammability and thermal stability studies of polymer layered-silicate (clay) nanocomposites," Applied Clay Science, vol. 15, no. 12, pp. 31-49, 1999.

[55] J. W. Gilman, C. L. Jackson, A. B. Morgan et al., "Flammability properties of polymer-layered-silicate nanocomposites. Polypropylene and polystyrene nanocomposites "," Chemistry of Materials, vol. 12, no. 7, pp. 1866-1873, 2000.

[56] A. Bonati, F. Merusi, G. Bochicchio et al., "Effect of nanoclay and conventional flame retardants on asphalt mixtures fire reaction," Construction and Building Materials, vol. 47, pp. 990-1000, 2013.

[57] S. A. Bagshaw, T. Kemmitt, M. Waterland, and S. Brooke, "Effect of blending conditions on nano-clay bitumen nanocomposite properties," Road Materials and Pavement Design, pp. 1-22, 2018.

[58] G. Liu, S. Wu, M. van de Ven, J. Yu, and A. Molenaar, "Structure and artificial ageing behavior of organo montmorillonite bitumen nanocomposites," Applied Clay Science, vol. 72, pp. 49-54, 2013.

[59] L. Li, S. Wu, G. Liu, T. Cao, and S. Amirkhanian, "Effect of organo-montmorillonite nanoclay on VOCs inhibition of bitumen," Construction and Building Materials, vol. 146, pp. 429-435, 2017.

[60] A. Zare-Shahabadi, A. Shokuhfar, and S. Ebrahimi-Nejad, "Microstructure and properties of nanoclay reinforced asphalt binders," Defect and Diffusion Forum, vol. 297-301, pp. 579-583, 2010.

[61] A. Zare-Shahabadi, A. Shokuhfar, and S. Ebrahimi-Nejad, "Preparation and rheological characterization of asphalt binders reinforced with layered silicate nanoparticles," Construction and Building Materials, vol. 24, no. 7, pp. 12391244, 2010.

[62] S. G. Jahromi and A. Khodaii, "Effects of nanoclay on rheological properties of bitumen binder," Construction and Building Materials, vol. 23, no. 8, pp. 2894-2904, 2009.

[63] S. Ghaffarpour Jahromi and A. Khodaii, "Identification effect of nanoclay on engineering properties of asphalt mixtures," AUT Journal of Modeling and Simulation, vol. 41, pp. 4957, 2009.

[64] S. G. Jahromi, M. S. M. Di NA, and S. Vossough, "Rutting and fatigue behavior of nanoclay modified bitumen," Iranian
Journal of Science and Technology. Transactions of Civil Engineering, vol. 35, pp. 277-281, 2011.

[65] H. L. Zhang, J. Y. Yu, L. H. Xue, and Z. C. Li, "Effect of montmorillonite organic modification on microstructures and ultraviolet aging properties of bitumen," Journal of Microscopy, vol. 244, no. 1, pp. 85-92, 2011.

[66] H. Zhang, D. Zhang, and C. Zhu, "Properties of bitumen containing various amounts of organic montmorillonite," Journal of Materials in Civil Engineering, vol. 27, no. 11, article 04015010, 2015.

[67] H. Zhang, C. Shi, J. Han, and J. Yu, "Effect of organic layered silicates on flame retardancy and aging properties of bitumen," Construction and Building Materials, vol. 40, pp. 1151-1155, 2013.

[68] H. L. Zhang, J. Y. Yu, and D. L. Kuang, "The effect of sodium and organic montmorillonites on the thermal aging properties of bitumen," Petroleum Science and Technology, vol. 31, no. 20, pp. 2074-2081, 2013.

[69] J.-Y. Yu, P.-C. Feng, H.-L. Zhang, and S.-P. Wu, "Effect of organo-montmorillonite on aging properties of asphalt," Construction and Building Materials, vol. 23, no. 7, pp. 2636-2640, 2009.

[70] X. Zhang, F. Ren, L. Zhang, D. Dong, K. Jiang, and Y. Lu, "Effects of the loading levels of organically modified montmorillonite on the flame-retardant properties of asphalt," Journal of Applied Polymer Science, vol. 131, no. 21, 2014.

[71] H. Zhang, H. Xu, X. Wang, and J. Yu, "Microstructures and thermal aging mechanism of expanded vermiculite modified bitumen," Construction and Building Materials, vol. 47, pp. 919-926, 2013.

[72] H. B. Zhang, H. L. Zhang, N. X. Ke, J. H. Huang, and C. Z. Zhu, "The effect of different nanomaterials on the longterm aging properties of bitumen," Petroleum Science and Technology, vol. 33, no. 4, pp. 388-396, 2015.

[73] Z. Chen, H. Zhang, C. Zhu, and B. Zhao, "Rheological examination of aging in bitumen with inorganic nanoparticles and organic expanded vermiculite," Construction and Building Materials, vol. 101, pp. 884-891, 2015.

[74] H. L. Zhang, N. X. Ke, and C. Z. Zhu, "Long-term aging properties of bitumen with expanded vermiculite and different inorganic nanoparticles," Petroleum Science and Technology, vol. 33, no. 17-18, pp. 1557-1562, 2015.

[75] C. Zhu, H. Zhang, G. Xu, and C. Wu, "Investigation of the aging behaviors of multi-dimensional nanomaterials modified different bitumens by Fourier transform infrared spectroscopy," Construction and Building Materials, vol. 167, pp. 536-542, 2018.

[76] H. Zhang, J. Yu, and D. Kuang, "Effect of expanded vermiculite on aging properties of bitumen," Construction and Building Materials, vol. 26, no. 1, pp. 244-248, 2012.

[77] J. Yu, X. Wang, L. Hu, and Y. Tao, "Effect of various organomodified montmorillonites on the properties of montmorillonite/ bitumen nanocomposites," Journal of Materials in Civil Engineering, vol. 22, no. 8, pp. 788-793, 2010.

[78] L. M. Mahdi, R. Muniandy, R. B. Yunus, S. Hasham, and E. Aburkaba, "Effect of short term aging on organic montmorillonite nanoclay modified asphalt," Indian Journal of Science and Technology, vol. 6, pp. 5434-5442, 2013.

[79] Walters, "Enhancing asphalt rheological behavior and aging susceptibility using bio-char and nano-clay," American 
Journal of Engineering and Applied Sciences, vol. 7, no. 1, pp. 66-76, 2014.

[80] M. E. Abdullah, K. A. Zamhari, M. R. Hainin, E. A. Oluwasola, N. A. Hassan, and N. I. M. Yusoff, "Engineering properties of asphalt binders containing nanoclay and chemical warm-mix asphalt additives," Construction and Building Materials, vol. 112, pp. 232-240, 2016.

[81] H. R. Zamanizadeh, M. R. Shishesaz, I. Danaee, and D. Zaarei, "Evaluation of the effects of nanoclay addition on the corrosion resistance of bituminous coating," Iranian Journal of Oil \& Gas Science and Technology, vol. 4, pp. 1526, 2015.

[82] H. R. Zamanizadeh, M. R. Shishesaz, I. Danaee, and D. Zaarei, "Investigation of the corrosion protection behavior of natural montmorillonite clay/bitumen nanocomposite coatings," Progress in Organic Coating, vol. 78, pp. 256-260, 2015.

[83] G. Polacco, S. Filippi, F. Merusi, and G. Stastna, "A review of the fundamentals of polymer-modified asphalts: asphalt/ polymer interactions and principles of compatibility," Advances in Colloid and Interface Science, vol. 224, pp. 72$112,2015$.

[84] F. Merusi, F. Giuliani, S. Filippi, and G. Polacco, "A model combining structure and properties of a 160/220 bituminous binder modified with polymer/clay nanocomposites. A rheological and morphological study," Materials and Structures, vol. 47, no. 5, pp. 819-838, 2014.

[85] H. Zhang, X. Jia, J. Yu, and L. Xue, "Effect of expanded vermiculite on microstructures and aging properties of styrene-butadiene-styrene copolymer modified bitumen," Construction and Building Materials, vol. 40, pp. 224230, 2013.

[86] L. G. A. T. Farias, J. L. Leitinho, B. . C. Amoni et al., "Effects of nanoclay and nanocomposites on bitumen rheological properties," Construction and Building Materials, vol. 125, pp. 873-883, 2016.

[87] B. Golestani, F. Moghadas Nejad, and S. Sadeghpour Galooyak, "Performance evaluation of linear and nonlinear nanocomposite modified asphalts," Construction and Building Materials, vol. 35, pp. 197-203, 2012.

[88] B. Golestani, B. H. Nam, F. Moghadas Nejad, and S. Fallah, "Nanoclay application to asphalt concrete: characterization of polymer and linear nanocomposite-modified asphalt binder and mixture," Construction and Building Materials, vol. 91, pp. 32-38, 2015.

[89] G. Polacco, P. Křriž, S. Filippi, J. Stastna, D. Biondi, and L. Zanzotto, "Rheological properties of asphalt/SBS/clay blends," European Polymer Journal, vol. 44, no. 11, pp. 3512-3521, 2008.

[90] M. Jasso, D. Bakos, J. Stastna, and L. Zanzotto, "Conventional asphalt modified by physical mixtures of linear SBS and montmorillonite," Applied Clay Science, vol. 70, pp. 37-44, 2012.

[91] M. Jasso, D. Bakos, D. MacLeod, and L. Zanzotto, "Preparation and properties of conventional asphalt modified by physical mixtures of linear SBS and montmorillonite clay," Construction and Building Materials, vol. 38, pp. 759-765, 2013.

[92] J. Yu, L. Wang, X. Zeng, S. Wu, and B. Li, "Effect of montmorillonite on properties of styrene-butadiene-styrene copolymer modified bitumen," Polymer Engineering and Science, vol. 47, no. 9, pp. 1289-1295, 2007.
[93] X. D. Tang, X. L. Kong, Z. G. He, and J. Li, "Nano-montmorillonite/SBS composite modified asphalt: preparation and aging property," Materials Science Forum, vol. 688, pp. 175179, 2011.

[94] C. Ouyang, S. Wang, Y. Zhang, and Y. Zhang, "Preparation and properties of styrene-butadiene-styrene copolymer/kaolinite clay compound and asphalt modified with the compound," Polymer Degradation and Stability, vol. 87, no. 2, pp. 309-317, 2005.

[95] S. S. Galooyak, B. Dabir, A. E. Nazarbeygi, and A. Moeini, "Rheological properties and storage stability of bitumen/ SBS/montmorillonite composites," Construction and Building Materials, vol. 24, no. 3, pp. 300-307, 2010.

[96] S. S. Galooyak, B. Dabir, A. E. Nazarbeygi, A. Moeini, and B. Berahman, "The effect of nanoclay on rheological properties and storage stability of SBS-modified bitumen," Petroleum Science and Technology, vol. 29, no. 8, pp. 850-859, 2011.

[97] Y.-P. Wang, D.-J. Liu, Y.-F. Li, Y.-P. Wang, and J.-M. Gao, "Preparation and properties of asphalts modified with SBS/ organobentonite blends," Polymers and Polymer Composites, vol. 14 , no. 4 , pp. 403-411, 2006.

[98] F. Khodary, "Longer fatigue life for asphalt pavement using (SBS@clay) nanocomposite,” International Journal of Current Engineering and Technology, vol. 5, no. 2, 2015, http://inpressco.com/wp-content/uploads/2015/03/ Paper64949-954.pdf.

[99] C. Fang, R. Yu, Y. Li, M. Zhang, J. Hu, and M. Zhang, "Preparation and characterization of an asphalt-modifying agent with waste packaging polyethylene and organic montmorillonite," Polymer Testing, vol. 32, no. 5, pp. 953-960, 2013.

[100] R. Yu, C. Fang, P. Liu, X. Liu, and Y. Li, "Storage stability and rheological properties of asphalt modified with waste packaging polyethylene and organic montmorillonite," Applied Clay Science, vol. 104, pp. 1-7, 2015.

[101] M. Sadeque and K. A. Patil, "Marshall properties of waste polymer and nanoclay modified bitumen," Facta universitatis - series: Architecture and Civil Engineering, vol. 12, no. 1, pp. 1-9, 2014.

[102] C. Fang, R. Yu, Y. Zhang, J. Hu, M. Zhang, and X. Mi, "Combined modification of asphalt with polyethylene packaging waste and organophilic montmorillonite," Polymer Testing, vol. 31, no. 2, pp. 276-281, 2012.

[103] M. Mohammadiroudbari, A. Tavakoli, M. K. Razavi Aghjeh, and M. Rahi, "Effect of nanoclay on the morphology of polyethylene modified bitumen," Construction and Building Materials, vol. 116, pp. 245-251, 2016.

[104] M. S. Sureshkumar, S. Filippi, G. Polacco, I. Kazatchkov, J. Stastna, and L. Zanzotto, "Internal structure and linear viscoelastic properties of EVA/asphalt nanocomposites," European Polymer Journal, vol. 46, no. 4, pp. 621-633, 2010.

[105] S. S. Markanday, J. Stastna, G. Polacco, S. Filippi, I. Kazatchkov, and L. Zanzotto, "Rheology of bitumen modified by EVA-organoclay nanocomposites," Journal of Applied Polymer Science, vol. 118, no. 1, pp. 557-565, 2010.

[106] S. Zapién-Castillo, J. L. Rivera-Armenta, M. Y. Chávez-Cinco, B. A. Salazar-Cruz, and A. M. Mendoza-Martínez, "Physical and rheological properties of asphalt modified with SEBS/ montmorillonite nanocomposite," Construction and Building Materials, vol. 106, pp. 349-356, 2016. 
[107] C. Ouyang, S. Wang, Y. Zhang, and Y. Zhang, "Thermo-rheological properties and storage stability of SEBS/kaolinite clay compound modified asphalts," European Polymer Journal, vol. 42, no. 2, pp. 446-457, 2006.

[108] F. Zhang, C. Hu, and Y. Zhang, "Influence of montmorillonite on ageing resistance of styrene-ethylene/butylenestyrene-modified asphalt," Journal of Thermal Analysis and Calorimetry, vol. 133, no. 2, pp. 893-905, 2018.

[109] J. Zhang, J. Wang, Y. Wu, W. Sun, and Y. Wang, "Investigation on thermo-rheological properties and stability of SBR modified asphalts containing palygorskite clay," Journal of Applied Polymer Science, vol. 113, no. 4, pp. 2524-2535, 2009.

[110] E. Santagata, O. Baglieri, L. Tsantilis, G. Chiappinelli, and D. Dalmazzo, "Bituminous-based nanocomposites with improved high-temperature properties," Composites. Part B, Engineering, vol. 99, pp. 9-16, 2016.

[111] H. Yao, Z. You, L. Li et al., "Performance of asphalt binder blended with non-modified and polymer-modified nanoclay," Construction and Building Materials, vol. 35, pp. 159170, 2012.

[112] F. J. Ortega, F. J. Navarro, M. García-Morales, and T. McNally, "Effect of shear processing on the linear viscoelastic behaviour and microstructure of bitumen/montmorillonite/MDI ternary composites," Journal of Industrial and Engineering Chemistry, vol. 48, pp. 212-223, 2017.

[113] F. J. Ortega, C. Roman, F. J. Navarro, M. García-Morales, and T. McNally, "Physico-chemistry control of the linear viscoelastic behaviour of bitumen/montmorillonite/MDI ternary composites: effect of the modification sequence," Fuel Processing Technology, vol. 143, pp. 195-203, 2016.

[114] F. J. Ortega, F. J. Navarro, M. García-Morales, and T. McNally, "Thermo-mechanical behaviour and structure of novel bitumen/nanoclay/MDI composites," Composites. Part B, Engineering, vol. 76, pp. 192-200, 2015.

[115] M. J. Martín-Alfonso, P. Partal, F. J. Navarro, M. GarcíaMorales, and C. Gallegos, "Use of a MDI-functionalized reactive polymer for the manufacture of modified bitumen with enhanced properties for roofing applications," European Polymer Journal, vol. 44, no. 5, pp. 1451-1461, 2008.

[116] M. Shivokhin, M. García-Morales, P. Partal, A. A. Cuadri, and C. Gallegos, "Rheological behaviour of polymermodified bituminous mastics: a comparative analysis between physical and chemical modification," Construction and Building Materials, vol. 27, no. 1, pp. 234-240, 2012.

[117] V. Carrera, P. Partal, M. García-Morales, C. Gallegos, and A. Páez, "Influence of bitumen colloidal nature on the design of isocyanate-based bituminous products with enhanced rheological properties," Industrial and Engineering Chemistry Research, vol. 48, no. 18, pp. 8464-8470, 2009.

[118] M. J. Martín-Alfonso, P. Partal, F. J. Navarro, M. GarcíaMorales, and C. Gallegos, "Role of water in the development of new isocyanate-based bituminous products," Industrial and Engineering Chemistry Research, vol. 47, no. 18, pp. 6933-6940, 2008.

[119] F. Navarro, P. Partal, M. Garciamorales, F. Martinezboza, and C. Gallegos, "Bitumen modification with a low-molecularweight reactive isocyanate-terminated polymer," Fuel, vol. 86, no. 15, pp. 2291-2299, 2007.

[120] A. A. Cuadri, M. García-Morales, F. J. Navarro, G. D. Airey, and P. Partal, "End-performance evaluation of thioureamodified bituminous binders through viscous flow and linear viscoelasticy testing," Rheologica Acta, vol. 52, no. 2, pp. 145154, 2013.

[121] Q. Wang and D. O'Hare, "Recent advances in the synthesis and application of layered double hydroxide (LDH) nanosheets," Chemical Reviews, vol. 112, no. 7, pp. 4124-4155, 2012.

[122] P. Q. Cui, H. G. Zhou, C. Li, S. P. Wu, and Y. Xiao, "Characteristics of using layered double hydroxides to reduce the VOCs from bituminous materials," Construction and Building Materials, vol. 123, pp. 69-77, 2016.

[123] P. Cui, S. Wu, Y. Xiao, M. Wan, and P. Cui, "Inhibiting effect of layered double hydroxides on the emissions of volatile organic compounds from bituminous materials," Journal of Cleaner Production, vol. 108, pp. 987-991, 2015.

[124] C. Peng, J. Yu, Z. Zhao et al., "Preparation and properties of a layered double hydroxide deicing additive for asphalt mixture," Cold Regions Science and Technology, vol. 110, pp. 70-76, 2015.

[125] C. Peng, J. Yu, Z. Zhao et al., "Synthesis and properties of a clean and sustainable deicing additive for asphalt mixture," PLoS One, vol. 10, no. 1, article e0115721, 2015.

[126] W. Shi, Y. Lin, S. Zhang et al., "Study on UV-shielding mechanism of layered double hydroxide materials," Physical Chemistry Chemical Physics, vol. 15, no. 41, pp. 1821718222, 2013.

[127] S. Xu, J. Yu, C. Zhang, T. Yao, and Y. Sun, "Effect of salicylic acid intercalated layered double hydroxides on ultraviolet aging properties of bitumen," Materials and Structures, vol. 49, no. 4, pp. 1235-1244, 2016.

[128] S. Xu, J. Yu, W. Wu, L. Xue, and Y. Sun, "Synthesis and characterization of layered double hydroxides intercalated by UV absorbents and their application in improving UV aging resistance of bitumen," Applied Clay Science, vol. 114, pp. 112-119, 2015.

[129] S. Xu, L. Li, J. Yu, C. Zhang, J. Zhou, and Y. Sun, "Investigation of the ultraviolet aging resistance of organic layered double hydroxides modified bitumen," Construction and Building Materials, vol. 96, pp. 127-134, 2015.

[130] S. Xu, J. Yu, C. Zhang, and Y. Sun, "Effect of ultraviolet aging on rheological properties of organic intercalated layered double hydroxides modified asphalt," Construction and Building Materials, vol. 75, pp. 421-428, 2015.

[131] S. Xu, J. Yu, Y. Sun, and S. Wu, "Synthesis and characterization of organic intercalated layered double hydroxides and their application in bitumen modification," Materials Chemistry and Physics, vol. 152, pp. 54-61, 2015.

[132] Z. J. Zhao, S. Xu, W. F. Wu, J. Y. Yu, and S. P. Wu, “The aging resistance of asphalt containing a compound of LDHs and antioxidant," Petroleum Science and Technology, vol. 33, no. 7, pp. 787-793, 2015.

[133] S. Xu, Y. B. Sun, and J. Y. Yu, "The effect of zinc doped Mg-Al LDHs on ultraviolet aging resistance of asphalt," Petroleum Science and Technology, vol. 33, no. 3, pp. 335-343, 2015.

[134] X. Liu, S. Wu, L. Pang, Y. Xiao, and P. Pan, "Fatigue properties of layered double hydroxides modified asphalt and Its mixture," Advances in Materials Science and Engineering, vol. 2014, Article ID 868404, 6 pages, 2014.

[135] S. Wu, J. Han, L. Pang, M. Yu, and T. Wang, "Rheological properties for aged bitumen containing ultraviolet light resistant materials," Construction and Building Materials, vol. 33, pp. 133-138, 2012. 
[136] C. Zhang, J. Yu, S. Xu, L. Xue, and Z. Cao, "Influence of UV aging on the rheological properties of bitumen modified with surface organic layered double hydroxides," Construction and Building Materials, vol. 123, pp. 574-580, 2016.

[137] C. Zhang, J. Yu, K. Feng, L. Xue, and D. Xie, "Synthesis and characterization of triethoxyvinylsilane surface modified layered double hydroxides and application in improving UV aging resistance of bitumen," Applied Clay Science, vol. 120, pp. 1-8, 2016.

[138] C. Peng, J. Dai, J. Yu, and J. Yin, "Intercalation of pmethycinnamic acid anion into $\mathrm{Zn}$ - $\mathrm{Al}$ layered double hydroxide to improve UV aging resistance of asphalt," AIP Advances, vol. 5, no. 2, article 027133, 2015.

[139] X. Liu, S. Wu, G. Liu, and L. Li, "Optical and UV-aging properties of LDH-modified bitumen," Materials, vol. 8, no. 7, pp. 4022-4033, 2015.

[140] X. Liu, S. Wu, G. Liu, and L. Li, "Effect of ultraviolet aging on rheology and chemistry of LDH-modified bitumen," Materials, vol. 8, no. 8, pp. 5238-5249, 2015.

[141] G. Wang, D. Rao, K. Li, and Y. Lin, "UV blocking by Mg-ZnAl layered double hydroxides for the protection of asphalt road surfaces," Industrial and Engineering Chemistry Research, vol. 53, no. 11, pp. 4165-4172, 2014.

[142] J. Wang, S. Wu, J. Han, and X. Liu, "Rheological properties of asphalt modified by supramolecular UV resistant materialLDHs," Journal of Wuhan University of TechnologyMaterials Science Edition, vol. 27, no. 4, pp. 805-809, 2012.

[143] W. Zeng, S. Wu, Y. Xiao, Z. Chen, and Y. Sun, "Low temperature properties of UV aged asphalts containing layered double hydroxides modifier," Journal of Applied Biomaterials \& Functional Materials, vol. 14, Supplement 1, pp. 73-76, 2016.

[144] Y. Li, S. Wu, L. Pang, Q. Liu, Z. Wang, and A. Zhang, "Investigation of the effect of $\mathrm{Mg}-\mathrm{Al}-\mathrm{LDH}$ on pavement performance and aging resistance of styrene-butadiene-styrene modified asphalt," Construction and Building Materials, vol. 172, pp. 584-596, 2018.

[145] Y. Li, S. Wu, Y. Dai et al., "Investigation of sodium stearate organically modified LDHs effect on the anti aging properties of asphalt binder," Construction and Building Materials, vol. 172, pp. 509-518, 2018.

[146] L. Pang, K. Liu, S. Wu, M. Lei, and Z. Chen, "Effect of LDHs on the aging resistance of crumb rubber modified asphalt," Construction and Building Materials, vol. 67, pp. 239-243, 2014.

[147] S. Filippi, M. Paci, G. Polacco, N. T. Dintcheva, and P. Magagnini, "On the interlayer spacing collapse of Cloisite ${ }^{\circledR}$ 30B organoclay," Polymer Degradation and Stability, vol. 96, no. 5, pp. 823-832, 2011. 


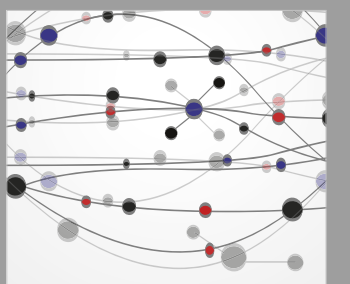

The Scientific World Journal
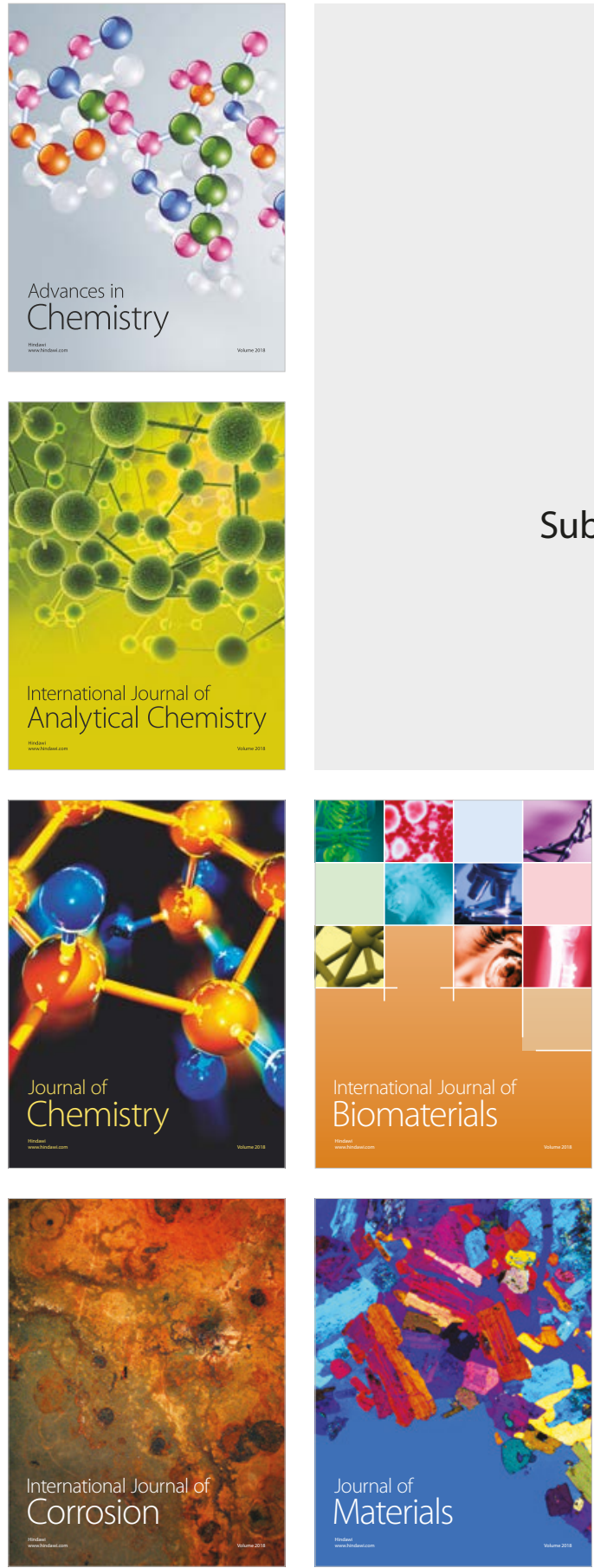

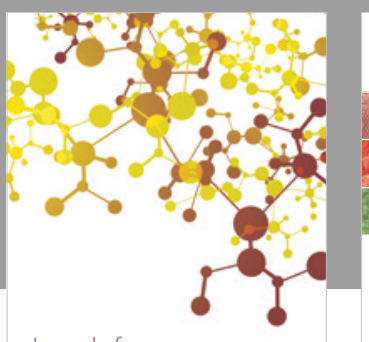

Journal of

Applied Chemistry
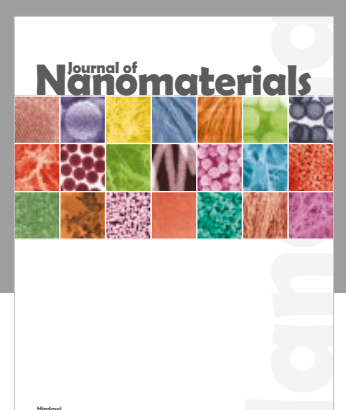

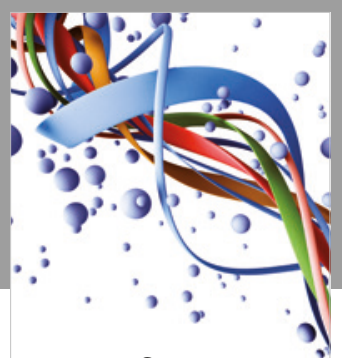

Scientifica

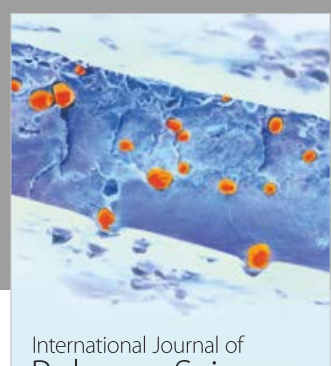

Polymer Science

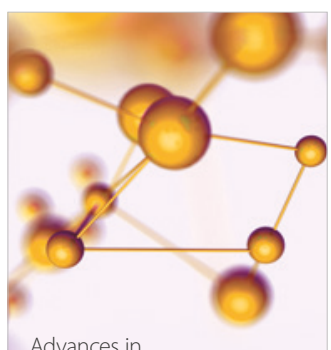

Physical Chemistry
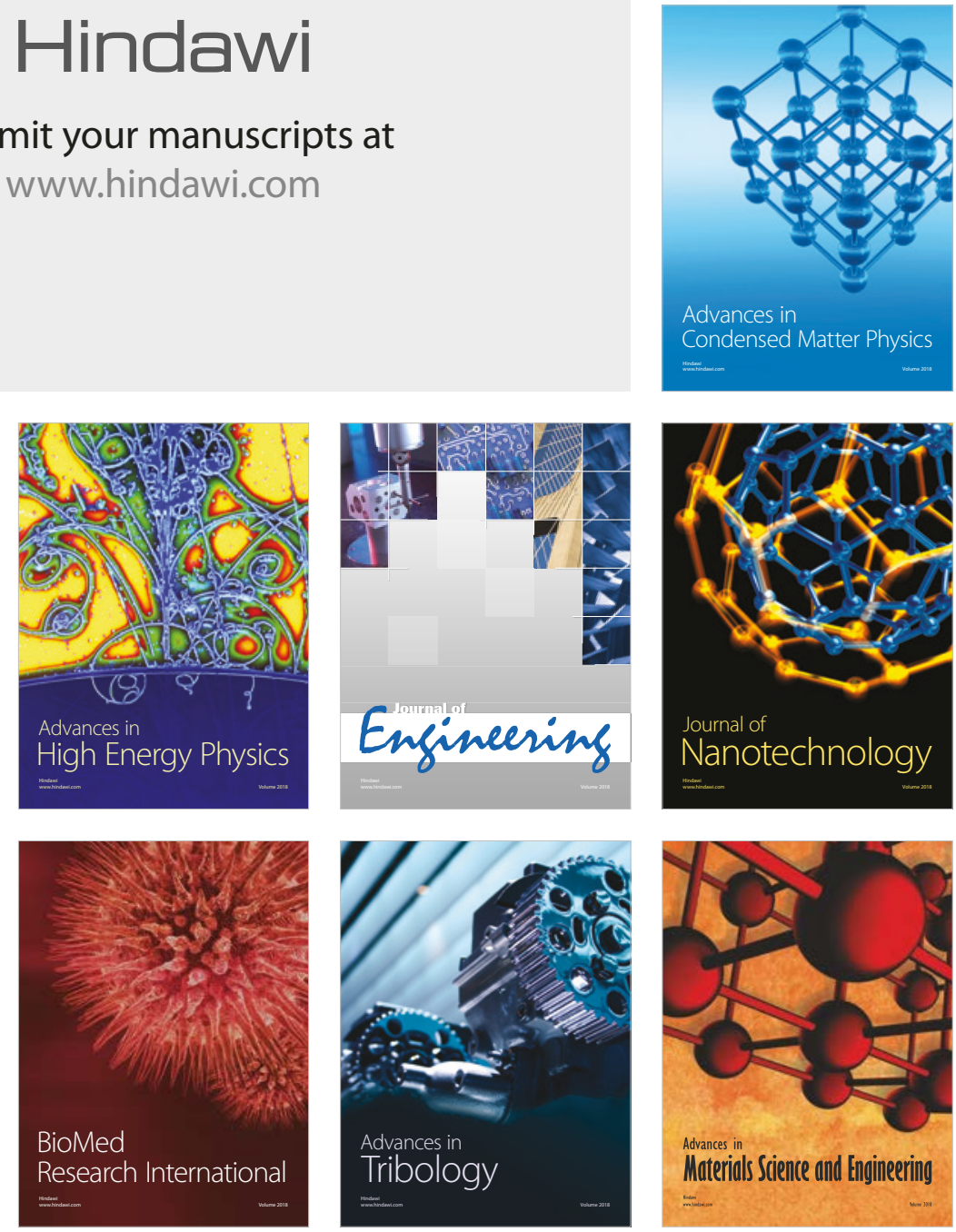